\title{
The alarmin interleukin-1a triggers secondary degeneration through reactive astrocytes and endothelium after spinal cord injury
}

\section{Floriane Bretheau}

Centre de recherche du Centre hospitalier universitaire (CHU) de Québec-Université Laval

\section{Adrian Castellanos-Molina}

Centre de recherche du Centre hospitalier universitaire ( $\mathrm{CHU}$ ) de Québec-Université Laval

\section{Benoit Mailhot}

Centre de recherche du Centre hospitalier universitaire (CHU) de Québec-Université Laval

\section{Maxime Kusik}

Centre de recherche du Centre hospitalier universitaire (CHU) de Québec-Université Laval

\section{Dominic Belanger}

Centre de recherche du Centre hospitalier universitaire (CHU) de Québec-Université Laval

\section{Martine Lessard}

Laval University

\section{Nicolas Vallières}

Laval University

\section{Xiaoyu Liu}

The Ohio State University

\section{Ning Quan}

Florida Atlantic University

Steve Lacroix ( $\sim$ Steve.Lacroix@crchul.ulaval.ca )

Centre de recherche du Centre hospitalier universitaire (CHU) de Québec-Université Laval https://orcid.org/0000-0003-0781-6371

\section{Article}

Keywords: Cytokine, danger signal, endothelial cell, interleukin-1, neutrophil, neuroinflammation.

Posted Date: June 14th, 2021

DOI: https://doi.org/10.21203/rs.3.rs-580331/v1

License: (c) (1) This work is licensed under a Creative Commons Attribution 4.0 International License. Read Full License 
Version of Record: A version of this preprint was published at Nature Communications on October 2nd, 2022. See the published version at https://doi.org/10.1038/s41467-022-33463-x. 


\section{Abstract}

Spinal cord injury (SCl) triggers neuroinflammation, and subsequently secondary degeneration and oligodendrocyte (OL) death. We report that the alarmin interleukin (IL)-1a is released by damaged microglia after SCl. Intra-cisterna magna injection of IL-1a in mice rapidly induced neutrophil infiltration and $\mathrm{OL}$ death throughout the spinal cord, mimicking what is seen at sites of SCl. These effects were abolished by co-treatment with the IL-1R1 antagonist anakinra, as well as in IL-1R1-knockout mice which showed enhanced locomotor recovery after SCl. Conditional restoration of IL-1R1 expression in astrocytes or endothelial cells (ECs), but not in OLs or microglia, restored IL-1a-induced effects, while astrocyte- or EC-specific /11r1 deletion reduced OL loss. Conditioned medium derived from IL-1astimulated astrocytes is toxic for OLs; further, IL-1 a-stimulated astrocytes generate reactive oxygen species (ROS) and blocking ROS production in IL-1a-treated or SCI mice prevented OL loss. Thus, after $\mathrm{SCl}$, microglia release IL-1a, which induces astrocyte- and EC-mediated OL degeneration.

\section{Introduction}

The pathophysiology of spinal cord injury ( $\mathrm{SCl}$ ) is divided into two distinct phases: the primary damage and the secondary damage ${ }^{1,2}$. The initial mechanical trauma caused by $\mathrm{SCl}$, characterized by the impact with possible persisting compression, leads to a reduced spinal cord blood flow and ischemia, an increased permeability of the blood-spinal cord barrier (BSCB), and the development of hemorrhages at the lesion site, conditions leading to cell death in the first few minutes to hours following the injury. These processes rapidly lead to a series of biochemical changes, characterized by the production of excitatory amino acids, free radicals, eicosanoids, cytokines and other inflammatory molecules, ultimately culminating in a progressive wave of secondary damage ${ }^{3}$. The transition from primary to secondary damage is triggered, at least in part, by the release of the intracellular content of necrotic cells, in particular danger-associated molecular patterns (DAMPs, also referred to as alarmins). Most prevalent among DAMPs in the injured CNS are nucleic acids, nucleotide derivatives and chromatin-associated proteins, including ATP, high-mobility group box (HMGB) proteins, interleukin (IL)-33 and IL-1 $a^{4-9}$. Thus, DAMPs released after $\mathrm{SCl}$ drive neuroinflammation and secondary tissue damage, but the relationship between these processes remains poorly understood.

We recently established that microglia and/or macrophages at sites of SCI rapidly produce the alarmin IL$1 \mathrm{a}$, which in return triggers neuroinflammation and locomotor deficits ${ }^{7}$. The presence of DAMPs at sites of $\mathrm{SCl}$ has also been associated with the production and release of inflammatory mediators, such as the proinflammatory cytokines IL-1 $\beta$ and tumor necrosis factor (TNF). Of particular interest is the fact that CNS endothelial cells (ECs) abundantly express both IL-1R1 and TNF receptor 1 (TNFR1) and are readily activated by this inflammatory environment ${ }^{10,11}$. Activation of endothelial IL-1R1 and TNFR1 typically results in multiple responses, including cytokine and chemokine release ${ }^{12,13}$, expression of cell adhesion molecules ${ }^{14,15}$, disruption of vascular permeability ${ }^{16,17}$, and leukocyte trafficking ${ }^{15}$. Astrocytes, which are major contributors to glial scar formation after $\mathrm{SCl}^{18}$, also react quickly to these inflammatory 
mediators. Using rodent primary CNS cell cultures and post-mortem brain tissue from patients with various neurodegenerative diseases, Liddelow and colleagues recently found that microglia-derived cytokines and growth factors determine whether astrocytes will have neurotoxic or pro-survival effects ${ }^{19}$, although it is generally acknowledged that reactive astrocytes may adopt multiple states ${ }^{20}$. Notably, a subtype of reactive astrocytes, termed A1 astrocytes, activated by microglia-derived IL-1a (but not IL-1ß), TNF and complement component $1 \mathrm{q}(\mathrm{C} 1 \mathrm{q})$, was suggested to play a role in the mechanisms leading to the death of OLs and neurons in diseases such as Alzheimer's, Huntington's and Parkinson's disease, amyotrophic lateral sclerosis and multiple sclerosis. However, not all forms of microglia and astrocyte responses have a detrimental impact on functional recovery in the context of $\mathrm{SCl}$, as depletion of these cells caused disruption of scar formation, enhanced parenchymal immune infiltrates, as well as reduced $\mathrm{OL}$ and neuronal survival ${ }^{21,22}$. To what extent, and using which signals, microglia, astrocytes, ECs and blood-derived immune cells are driving secondary degeneration after $\mathrm{SCl}$ therefore remains an open question.

The mechanisms underlying secondary tissue damage after $\mathrm{SCl}$ generate an environment this is particularly toxic for OLs ${ }^{23,24}$. In mice, the number of OLs rapidly decreases during the first 24 hours post$\mathrm{SCl}$, with a maximum loss at 1 week post-injury ${ }^{25}$. Apoptotic death of OLs has been detected in degenerating white matter tracts of rodents, monkeys and humans until at least 2 to 3 weeks post-SCl ${ }^{26-}$ 30 . Whether this loss of OLs is directly responsible for the demyelination and conduction failure observed in axons that survived the initial trauma ${ }^{31-34}$, and perhaps some of the behavioral deficits detected after $\mathrm{SCl}$, remains however uncertain. Although the inflammatory response that takes place following an injury to non-CNS tissue often leads to repair, a similar response in the injured CNS could cause secondary damage ${ }^{3}$. As mentioned, the neuroimmune response that develops after $\mathrm{SCl}$ is initiated by the release of DAMPs from disrupted glial cells, neurons and ECs, leading to the recruitment of leukocytes from the blood. Given the dichotomic nature of the neuroimmune response and its overall complexity, it is therefore critical to identify the cells that release the most important DAMPs during the acute phase of $\mathrm{SCl}$. Equally important is to study the effects of DAMPs on the CNS environment and the periphery.

Following up on our recent discovery that deletion of the I/1a gene protects OLs and reduces tissue damage after $\mathrm{SCl}$, we investigated the cellular and molecular mechanisms that underlie IL-1a-dependent effects in the normal and injured mouse spinal cord. We found that microglia-derived IL-1a induces death of OLs through astrocytic and endothelial IL-1R1. More specifically, stimulation of astrocytic IL-1R1 by IL1a converted these cells into a reactive phenotype characterized by enhanced production and release of reactive oxygen species (ROS) that are toxic to OLs. Accordingly, blocking ROS production in IL-1ainjected mice and $\mathrm{SCl}$ mice prevented $\mathrm{OL}$ death. Thus, blocking IL-1R1 signaling or ROS production may be a promising therapeutic avenue to prevent loss of OLs following a CNS insult.

\section{Results}

IL-1a is released by injured microglia during the early acute phase of $\mathrm{SCl}$ 
We previously showed that microglia and/or macrophages are the main producers of IL-1a after SCI ${ }^{7}$. To clarify which of these two cell types is the major contributor to the production of IL-1a, we performed immunofluorescence staining against IL-1a on spinal cord tissue sections from $C \times 3 c r 1$ CreER:: R26-TdT mice killed at 4 hours post-SCI (Fig. 1A), which corresponds to the peak of IL-1a protein expression.

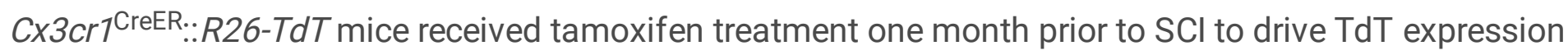
specifically in microglia, but not in peripheral myeloid cells, as established before ${ }^{22}$. Quantification revealed that nearly all $(95 \% \pm 5 \%)$ IL-1 a-positive (+) cells also express TdT, suggesting that they are microglia (Fig. 1B). To confirm this finding, microglia were depleted in vivo using PLX5622, a CSF1R inhibitor from Plexxikon. As shown in Suppl. Fig. 1, very few IL-1 $\mathrm{a}^{+}$cells were detected in the injured

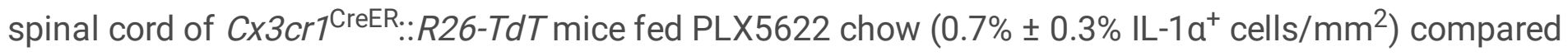
to those fed the control diet $\left(38.0 \pm 4.4 \mathrm{IL}-1 \mathrm{a}^{+}\right.$cells $\left./ \mathrm{mm}^{2}\right)$. Thus, our results show that microglia located at the lesion epicenter and surrounding damaged areas are the main cellular source of IL-1 a production after SCl.

Since IL-1 $\mathrm{a}$ is typically synthesized as a precursor protein and constitutively stored in the nucleus and cytoplasm of cells, consistent with its role as an alarmin, we next sought to determine the health status of IL-1a-producing microglia in the injured mouse spinal cord. Most IL- $1 \mathrm{a}^{+}$microglia had both damaged cell bodies and processes or exhibited retracted, swollen processes, indicative of an activated status (Fig. 1C$\mathrm{N})$. Confocal microscopy images revealed a homogenous distribution of the IL-1 a protein within the whole microglia (nucleus and cytoplasm). Together, these results show that damaged microglia release the alarmin IL-1a during the early acute phase of SCI.

\section{Acute central delivery of IL-1a in mice induces activation of glial cells throughout the spinal cord}

Trauma-induced necrotic cell death, as it occurs after $\mathrm{SCl}$, is likely to induce the release of several different alarmins at roughly the same time, as it was suggested for IL-1a, HMGB1, IL-33, and ATP 35,36. To be able to study the effect of IL-1a in a relatively simpler in vivo model, we injected murine recombinant IL-1a (rmIL-1a) intra-cisterna magna (i.c.m) to naïve C57BL/ 6 mice and examined the effects of the alarmin on the activation of glial cells in the spinal cord at different time points. Expression of the transcription factor Fos was used as marker of cell activation ${ }^{37}$. Immunostaining for Fos in spinal cord tissue sections from mice injected with rmIL-1a revealed that Sox $9^{+}$astrocytes and Olig2 ${ }^{+}$ oligodendrocytes (OLs) are activated as early as 1 hour post-injection (Fig. 2). The peak of activation for OLs and astrocytes was observed at 4 hours, with a total of $265.3 \pm 49.8 \mathrm{Fos}^{+} \mathrm{Olig}^{+}$cells $/ \mathrm{mm}^{2}$ and $131.3 \pm 15.9 \mathrm{Fos}^{+}$Sox $9^{+}$astrocytes $/ \mathrm{mm}^{2}$ in the thoracic spinal cord white matter (Fig. $2 \mathrm{H}, 0$ ). The number of activated OLs and astrocytes decreased afterward to $45.0 \pm 13.0 \mathrm{cells} / \mathrm{mm}^{2}$ and $16.0 \pm 5.5$ cells $/ \mathrm{mm}^{2}$, respectively, at 24 hours post-injection. For all time points examined, nearly zero Fos ${ }^{+}$cells were detectable in the spinal cord white matter of PBS-injected mice. Thus, it appears that spinal cord cell activation in response to IL-1a occurs following a precise chronological sequence of cellular events. 
Central delivery of IL-1a induces neutrophil infiltration into the neurovascular space and parenchyma of the spinal cord

Knowing that IL-1a initiates sterile inflammation by recruiting neutrophils in Matrigel plugs supplemented with necrotic cell products ${ }^{38}$, we next examined whether IL-1a injection resulted in the recruitment of $\mathrm{Ly}_{6 \mathrm{G}}{ }^{+}$neutrophils along the rostro-caudal spinal cord axis. From 1 to 4 hours after the injection of IL-1a, no $\mathrm{Ly} \mathrm{GG}^{+}$cells were observed in the spinal cord (Fig. 3A). However, the situation drastically changed at 24 hours, a time at which we observed a massive influx of neutrophils. As shown in Fig. 3B-C, neutrophils were found both in the neurovascular space and parenchyma of the spinal cord after i.c.m. injection of IL$1 a$ but not PBS. The neutrophil recruitment was transient, because neutrophil numbers were back to zero at 3 days post-injection (data not shown). Thus, also implicated in the cascade of cellular events elicited by IL-1a are infiltrating innate immune cells such as neutrophils, whose recruitment occurs after the activation of glial cells.

\section{IL-1a induces the death of mature oligodendrocytes in the mouse spinal cord}

Neuroinflammation has been suspected to be a major cause of the secondary degeneration that occurs after SCl. Thus, we next evaluated whether the presence of IL-1a in the spinal cord would affect cell health and homeostasis, with a special focus on cells of the OL lineage as this cell population was found to be particularly vulnerable to secondary damage after $\mathrm{SCl}^{29,30}$. Mature OLs were identified as cells that are immunopositive for both Olig2 and $\mathrm{CC} 1$ and specifically quantified in the spinal cord white matter. At 4 hours post-injection, no differences in numbers of Olig2 ${ }^{+} \mathrm{CC}^{+}$mature OLs were seen between mice injected with either PBS or IL-1a (Fig. 3D). However, the total number of mature OLs was reduced by approximately $40 \%$ in mice that received IL-1a i.c.m. compared to PBS-injected control mice at 24 hours (Fig. 3D-F). We counted on average $512.3 \pm 24.2$ Olig2 ${ }^{+} \mathrm{CC} 1^{+}$cells $/ \mathrm{mm}^{2}$ in the spinal cord white matter of mice injected with PBS compared to $302.6 \pm 32.6$ Olig2 ${ }^{+} \mathrm{CC} 1^{+}$cells $/ \mathrm{mm}^{2}$ in mice injected with IL-1a. Notably, the decrease in the number of mature OLs at 24 hours post-IL-1a injection was amplified at higher concentrations of the cytokine (data not shown), thus suggesting a dose-response effect.

\section{Mature oligodendrocytes are rapidly replaced following death by increased proliferation of oligodendrocyte lineage cells}

Mature OLs are a highly diverse cell population, but they all originate from a common oligodendrocyte precursor cell (OPC) whose proliferation and differentiation are regulated by extrinsic signals present in the cell microenvironment ${ }^{39}$. Considering that mature OLs are decimated during the early acute phase of $\mathrm{SCl}^{7}$, an effect that was mimicked by acute central delivery of IL-1a in the present study, we next investigated whether the $\mathrm{OL}$ cell population is restored upon death by performing in vivo $5^{\prime}$ bromodeoxyuridine (BrdU) experiments. As shown in Fig. 4A-D, the number of Olig2 ${ }^{+} \mathrm{BrdU}^{+}$cells was increased by $\sim 6.4$ fold in the spinal cord white matter of IL-1a-injected mice compared to the control group at 3 days post-injection. This finding was confirmed by immunofluorescence staining that showed the proliferative marker Ki67 to be augmented by 4.6-fold in the Olig2 cell population in response to IL- 
1a (Fig. 4E). Importantly, the number of mature OLs in the IL-1a group returned back to baseline values after 3-5 days (Fig. 4F). Altogether, these results suggest that the death of mature OLs induced by IL-1a is compensated for by the rapid proliferation of OL lineage cells.

\section{IL-1a induces neuroinflammation and OL cell death through IL-1R1 signaling}

As evidence suggests that IL-1R1 is the main signaling receptor for IL-1a, we postulated that IL-1R1 blockade using anakinra, a recombinant IL-1 receptor antagonist with greater affinity for IL-1R1 than IL-1a itself ${ }^{40}$, would reduce the central effects of the cytokine. When anakinra was administered concomitantly with rmIL-1a, the infiltration of neutrophils in the mouse spinal cord was completely blocked (Fig. 5A-C). Moreover, treatment with anakinra protected from IL-1a-induced OL cell death (Fig. 5D-F). Thus, blockade of IL-1R1 signaling is sufficient to abolish the potential pathophysiological effects of IL-1a in the spinal cord.

\section{Recovery of locomotor function is improved in mice lacking IL-1R1 after SCI}

Based on the previous findings, we postulated that mice deficient in IL-1R1 would exhibit reduced signs of secondary degeneration resulting in improved functional recovery after $\mathrm{SCl}$. Therefore, we investigated whether the absence of the $/ / 1 \mathrm{r} 1$ gene positively affects locomotor recovery after $\mathrm{SCl}$, as previously reported for $\| 17 a^{-/-}$mice ${ }^{7}$. Naïve $\left\|11 r^{-1},\right\| / 1 a^{-/-}$and WT mice all performed flawlessly and received perfect scores on the 9-point Basso Mouse Scale for locomotion (BMS) and the 11-point BMS subscore. The situation was however different after a moderate (50 kdyn) traumatic SCl. As shown in Suppl. Fig. 2, $\| 1 r^{-1-}$ mice recovered significantly better than WT mice, mimicking the neurological improvements observed in $/ / 1 a^{-/-}$mice. Together, these results suggest that global deficiency in IL-1R1 signaling contributes to better functional recovery after $\mathrm{SCl}$ by reducing early signs of secondary degeneration.

\section{IL-1R1 is expressed by both glial and endothelial cells in the mouse spinal cord}

Next, we assessed IL-1R1 protein expression in the main cell types that reside in the spinal cord. For this, we opted for an immunoblotting approach using membrane protein extracts derived from either specific primary cell types isolated from the normal CNS or cell lines. Immunoblot analysis revealed that IL-1R1 is expressed by CNS-ECs, OPCs, astrocytes and microglia (Suppl. Fig. 3). Intriguingly, the protein detected using the anti-IL-1R1 polyclonal antibody in OPCs and astrocytes was of a slightly lower molecular weight than the predicted 75-kDa IL-1R1 protein, suggesting the possibility that cells of the glial-restricted lineage could express a different form of the receptor. Along this line, we point out that IL-1R3 is identical to IL-1R1 at the $\mathrm{C}$ terminus, but with a shorter extracellular domain and a predicted molecular weight of about $66 \mathrm{kDa}^{41}$.

\section{Oligodendrocyte cell death is not directly mediated by IL-1a}

To investigate the mechanisms by which IL-1a mediates its effects, we took advantage of the IL-1R1restored mouse line developed by Liu et al. ${ }^{42}$. IL-1R1-restored mice, designed hereafter to as $/ / 1 \mathrm{r} \mathrm{r}^{\mathrm{r} / \mathrm{r}}$ mice, 
exhibit an IL-1R1 (and IL-1R3) knockout phenotype that can be reversed in a cell-specific manner by Cremediated recombination. First, we asked whether OL cell death could be mediated by a direct effect of IL1a on OLs. To address this question in vivo, we crossed $I / 1 r r^{r / r}$ mice to mice expressing an inducible Cre recombinase under the control of the Pdgfra promoter, thus restoring $/ / 1 r 1$ gene expression specifically in OPCs and their cell derivatives. To measure the efficiency of Cre-mediated IL-1R1 restoration in OL lineage cells, qPCR was used to amplify the floxed Neo cassette causing disruption of the $/ 11 r 1$ gene in PDGFRa ${ }^{+}$ OPCs and $\mathrm{O}^{+}$pro-OLs immunopanned from the adult mouse spinal cord. We estimated the restoration of $/ 11 \mathrm{r} 1$ gene expression to be around $20 \%$ and $25 \%$ of normal levels in PDGFRa ${ }^{+}$OPCs and $04^{+}$pro-OLs, respectively, in PdgfraCreER:://1 r $7^{r / r}$ mice (Fig. 6A). Based on Olig2 immunolabeling, the purity of the OPC and pro-OL cell populations used for total DNA extraction was estimated at $50 \%$ and $60 \%$, respectively (data not shown). Thus, this translates into a recombination rate of approximately $40 \%$ in both OL cell populations. As expected, no restoration of the wild-type I/1r1 allele was observed in OL lineage cells of $/ / 1 r r^{r / r}$ mice. Despite partial restoration of $/ / 1 r 1$ gene expression in OLs of $P d g f r a C r e E R:: / / 1 r 1^{r / r}$ mice, we failed to restore the infiltration of neutrophils and death of mature OLs in response to i.c.m. delivery of IL-

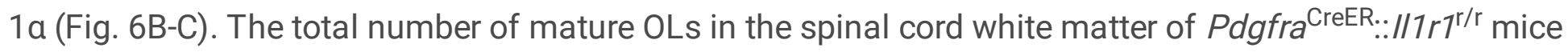
injected with IL-1a was similar to that of $/ / 1 r 7^{r / r}$ mice and animals injected with PBS (Fig. 6C). Moreover, we did not observe any significant effect of IL-1a on the death of primary mature OLs in vitro (see below). Altogether, these results suggest that IL-1a does not cause OL cell death by a direct mechanism of action.

\section{IL-1a mediates OL cell death independently of microglial IL-1R1}

As we previously established that IL-1a is released by microglia in the first few hours post-SCl and that these cells express IL-1R1, we next aimed to investigate whether IL-1a could have autocrine effects on microglia, promoting in return neuroinflammation and the death of mature OLs. To test this, we crossed C $\times 3 c r 7^{\mathrm{CreER}}$ and $/ / 1 r 7^{\mathrm{r} / \mathrm{r}}$ mice to restore IL-1R1 expression specifically in microglia in otherwise null mice. The efficiency of IL-1R1 restoration was estimated at approximately $65 \%$ in microglia isolated from the normal spinal cord of adult $C \times 3 c r 7^{\mathrm{CreER}:: / / 1} 1 \mathrm{r}^{\mathrm{r} / \mathrm{r}}$ mice (Fig. 7A). We next conducted an experiment in which

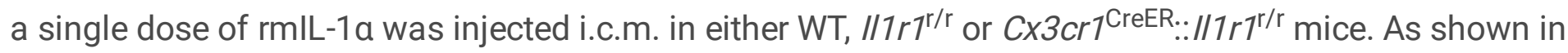
Fig. 7B, neutrophils infiltrated the spinal cord of WT mice, but not $/ 117^{\mathrm{r} / \mathrm{r}}$ or $C \times 3 c r 7^{\mathrm{CreER} .: . / 1} r^{\mathrm{r} / \mathrm{r}}$ mice, within 24 hours of the injection. Similarly, only WT mice responded to IL-1 a treatment with a significant decrease in OL cell number (Fig. 7C), suggesting that microglial IL-1R1 signaling does not mediate the central effects of IL-1a. However, when microglia were depleted using PLX5622, the number of neutrophils that infiltrated the spinal cord in response to acute i.c.m. delivery of IL-1 a increased from $165.0 \pm 22.3$ to $301.0 \pm 39.5{\mathrm{Ly} 6 \mathrm{G}^{+}}^{+}$cells $/ \mathrm{mm}^{2}$ (Fig. 7D-J). In parallel, the number of mature OLs further decreased in mice that received the combination of IL-1 $\mathrm{a}$ and PLX5622, passing from $353.3 \pm 22.5$ Olig ${ }^{+} \mathrm{CC}^{+} / \mathrm{mm}^{2}$ in the spinal cord white matter of PBS-injected WT mice, to $114.3 \pm 29.4$ Olig $2^{+} \mathrm{CC} 1^{+} / \mathrm{mm}^{2}$ in IL-1a-injected WT mice, and finally to $56.7 \pm 25.7 \mathrm{Olig} 2^{+} \mathrm{CC} 1^{+} / \mathrm{mm}^{2}$ in IL-1a-injected WT mice fed the PLX5622 diet (Fig. 7K). This indicates that the central effects of IL-1a are amplified in the absence of microglia, with nearly two times more infiltrating neutrophils and half the number of 
mature OLs in the spinal cord of microglia-depleted mice. Considering the existence of a decoy IL-1 receptor, IL-1R2, we next hypothesized that the protection conferred by microglia could have been provided by an upregulation of this receptor. To test this possibility, we took advantage of tamoxifeninducible $C \times 3 c r 7^{\text {CreER.: }}$ R26-TdT mice to isolate microglia specifically, with minimal contamination by blood-derived immune cells ${ }^{22}$. We then extracted total RNA from microglia at 24 hours post-injection of either PBS or rmIL-1 $a$ and measured I/1r2 mRNA levels using quantitative real-time PCR. Data showed that IL-1R2 is undetectable at the mRNA level in microglia of PBS-injected mice, but that its expression is dramatically increased in microglia following i.c.m. injection of IL-1a (Fig. 7L). Together, these results suggest that the mechanism by which IL-1a induces $\mathrm{OL}$ cell death in the spinal cord occurs independently of microglial IL-1R1 signaling. Rather, microglia appear to protect OLs by sequestering IL-1 cytokines within the extracellular compartment through the decoy IL-1R2.

\section{IL-1R1 signaling in CNS endothelial cells drives neutrophil infiltration and mediates part of the OL cell death response}

The expression of IL-1R1 by CNS ECs is well described in the literature. In previous studies, we and others have reported the importance of endothelial IL-1R1 signaling in the neuroinflammatory processes that take place at the blood-brain barrier (BBB) and BSCB in the experimental autoimmune encephalomyelitis (EAE) mouse model of multiple sclerosis ${ }^{13-15,43}$. To investigate the functional role of endothelial IL-1R1 in the central effects of IL-1a, Cdh $5^{\mathrm{CreER}}$ mice were crossed with $/ / 1 r 7^{\mathrm{r} / \mathrm{r}}$ or $/ / 1 r 7^{\mathrm{fl} / \mathrm{fl}}$ mice to restore or delete, respectively, IL-1R1 expression specifically in CNS ECs (Fig. 8). We determined that I/1r1 gene expression

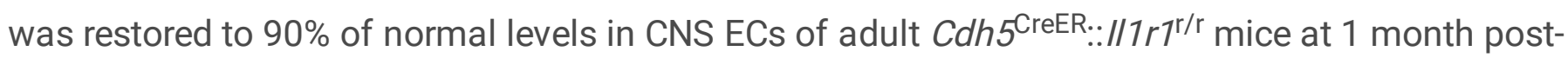
tamoxifen treatment (Fig. 8B). This restoration of endothelial IL-1R1 expression was sufficient to restore about $35 \%$ of the neutrophil infiltration observed after i.c.m. injection of rmlL-1a (Fig. 8C \& Suppl. Fig. 4AB). As shown in Fig. 8D and Suppl. Fig. 4C-D, the average number of mature OLs in the spinal cord of

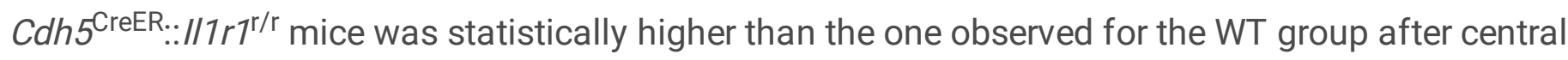
administration of IL-1a, but still reduced compared to IL-1R1-deficient $\left(I / 1 r 7^{r / r}\right)$ mice. Restoration of IL-1R1 expression in CNS ECs was, however, insufficient to restore locomotor deficits to the levels observed in SCI WT mice, as assessed using the BMS score (Fig. 8E-F). These results suggest that endothelial IL-1R1 signaling only partially contributes to the global effects of IL-1a in the pathogenesis of SCl. This prompted us to investigate the potential contribution of endothelial IL-1R1 in another transgenic mouse model, namely $C d h 5^{C r e E R}:: / 11 r 7^{f / f l}$ mice. In these mice, expression levels of the $/ / 1 r 1$ gene were reduced by nearly half in CNS ECs when compared to $/ 11 r^{f / / f l}$ control mice (Fig. 8G-H). In agreement with data presented in Fig. 8C, conditional knockout (CKO) of IL-1R1 specifically in CNS ECs also proved that endothelial IL-1R1 is at least in part responsible for the recruitment and infiltration of neutrophils in the spinal cord of mice at 24 hours post-i.c.m. injection of IL-1a (Fig. 8I \& Suppl. Fig. 4E-F). Notably, the IL-1amediated decrease in the number of mature spinal cord OLs was prevented by genetic deletion of the

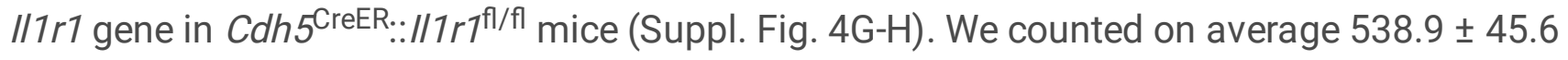

Olig2 ${ }^{+} \mathrm{CC} 1^{+} \mathrm{cells} / \mathrm{mm}^{2}$ in the spinal cord white matter of $C d h 5^{\mathrm{CreER} .:} / / 1 \mathrm{r} 7^{\mathrm{fl} / \mathrm{fl}}$ mice injected with PBS compared to $469.2 \pm 30.7$ Olig2 ${ }^{+} \mathrm{CC} 1^{+}$cells $/ \mathrm{mm}^{2}$ in those injected with IL-1a (Fig. 8J). This decrease was 
not statistically significant and did not recapitulate the magnitude of the OL cell loss detected in the two control mouse lines in response to IL-1a (i.e. $45-50 \%$ decrease). These loss-of-function effects caused by cKO of IL-1R1 in CNS ECs did not translate into any changes in terms of locomotor recovery (Fig. 8K-L). Thus, endothelial IL-1R1 signaling is at least partially responsible for the infiltration of neutrophils and death of mature OLs induced by IL-1a.

\section{IL-1a induces OL cell death in part through activation of IL-1R1 signaling in astrocytes}

In light of the recent studies reporting the existence of neurotoxic A1 astrocytes in various CNS disorders 19,44, we next investigated the contribution of astrocytic IL-1R1 signaling in IL-1a-mediated OL cell death. To examine this, Gfap Cre mice were crossed with either $\| / 1 r^{1 / r}$ or $/ / 1 r r^{f l / f l}$ mice to restore or delete, respectively, IL-1R1 expression specifically in astrocytes (Fig. 9). In brain astrocytes of neonate

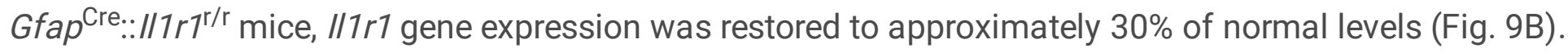
A partial restoration of IL-1R1 expression in astrocytes was however not sufficient to reestablish IL-1amediated neutrophil infiltration, as virtually no $\mathrm{Ly}_{6 \mathrm{G}^{+}}$cells were observed in the spinal cord of

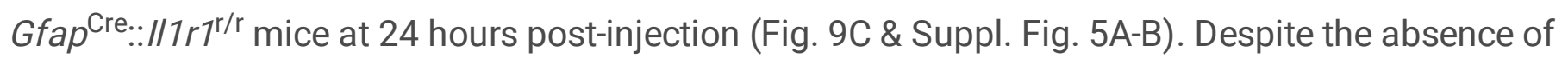
neutrophil recruitment, this level of restoration of IL-1R1 expression in astrocytes partially restored OL cell death induced by IL-1a (Suppl. Fig. 5C-D). Indeed, the number of mature OLs decreased by $35 \%$ in

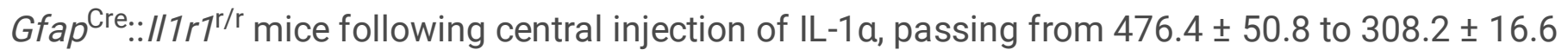
Olig ${ }^{+} \mathrm{CC}^{+}$cells $/ \mathrm{mm}^{2}$ (Fig. 9D). In comparison, $55 \%$ of the population of mature OLs died in response to central delivery of IL-a in WT mice, passing from $489.0 \pm 225.1$ to $225.6 \pm 34.0$ Olig2 ${ }^{+} \mathrm{CC} 1^{+} \mathrm{cells} / \mathrm{mm}^{2}$ in the thoracic spinal cord white matter. While WT mice performed significantly worse than IL-1R1-deficient $\left(/ / 1 r 7^{r / r}\right)$ mice on the BMS open-field locomotor scale after SCl, Gfap Cre.:.//1r $7^{r / r}$ mice performed identical to $/ 17 r 7^{r / r}$ mice (Fig. 9E-F). Importantly, the above findings were confirmed in another transgenic mouse

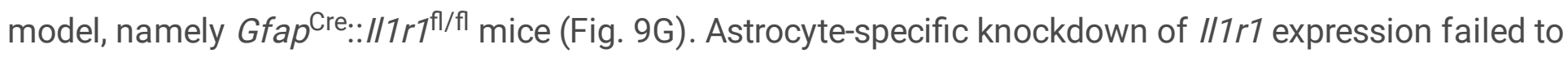
reduce neutrophil infiltration, but partially prevented OL cell death in response to IL-a administration compared to WT and $/ 17 r^{\text {fl/fl }}$ controls (Fig. 9H-J \& Suppl. Fig. 5E-H). However, partial deletion of the I/1r1 gene in astrocytes alone did not promote functional recovery in the context of SCl (Fig. 9K-L). Therefore, combining targeting of both astrocytic and endothelial IL-1R1, or their common downstream effector molecules, could prove synergistic and produce better outcomes in terms of preventing secondary degeneration and locomotor deficits after SCl.

\section{Blood-derived myeloid cells are not responsible for the killing of mature OLs}

To determine whether immune cells of the myeloid lineage could play a role in OL death induced by i.c.m. delivery of IL-1a, we depleted neutrophils and monocytes by repeated i.p. injections of high doses of the anti-Ly6C/Ly6G (Gr-1) antibody (Suppl. Fig. 6A). Mice presented with a significant decrease in granulocyte and monocyte counts in blood 1 day after the last injection of the Gr-1-depleting antibody regimen, regardless of whether they received IL-1a or PBS (Suppl. Fig. 6B-C). As treatment with the antiGr-1 antibody could have resulted in the masking of surface Ly6C/Ly6G antigens, thus preventing their 
subsequent detection by flow cytometry, the effectiveness of the depletion strategy was also validated in

$L y s M^{G F P}$ transgenic mice, which express the eGFP fluorescent protein in cells of granulo-myelomonocytic lineage. As shown in Suppl. Fig. 6D, the number of LysM-GFP+ cells per $\mathrm{mm}^{3}$ of blood was reduced by approximately $95 \%$ compared with saline-treated and isotype control-treated animals 1 day after the last injection of three high doses of anti-Gr-1. Importantly, the efficacy of the myeloid cell depletion strategy was also confirmed using blood and spinal cord tissue of $L y S M^{\text {GFP }}$ mice injected in the CSF with rmIL-1a (Suppl. Fig. 6D-H). Flow cytometry analysis revealed a decrease of roughly $60 \%$ in blood circulating LysM$\mathrm{GFP}^{+}$cells in fluorescent transgenic mice treated with the anti-Gr-1 antibody. Immunostaining showed about $70 \%$ fewer LysM-GFP ${ }^{+}$cells in the spinal cord of $L y s M^{\text {GFP }}$ mice treated with the anti-Gr-1 antibody $\left(32.4 \pm 9.0\right.$ cells $\left./ \mathrm{mm}^{2}\right)$ compared to saline- and isotype control-treated mice (101.8 \pm 43.1 and $102.4 \pm$ 31.0 cells $/ \mathrm{mm}^{2}$, respectively). Despite this important decrease in myeloid cell infiltration, the anti-Gr-1 treatment did not prevent or reduce the OL cell loss induced by IL-1 a (Suppl. Fig. 6I-L). We counted similar numbers of mature OLs in the saline, isotype control and anti-Gr1 groups, with $322.5 \pm 15.4,353.4 \pm 44.7$ and $282.2 \pm 33.1$ Olig $2^{+} \mathrm{CC}^{+}$cells $/ \mathrm{mm}^{2}$, respectively. Altogether, these results suggest that immune myeloid cells did not play a role in the death of mature spinal cord OLs observed after central IL-1a administration.

\section{IL-1a induces a reactive astrocyte phenotype that leads to the killing of mature OLs through the release of reactive oxygen species}

The complement component 3 (C3) protein was recently shown to be upregulated in a subtype of reactive astrocytes with potential neurotoxic effects in various CNS disorders ${ }^{19}$. Thus, we examined whether central administration of rmlL-1a would increase C3 expression in spinal cord astrocytes. We found that i.c.m. delivery of IL-1 $\mathrm{a}$ in C57BL/ 6 mice increased the total number of Sox $9^{+}$cells expressing C3 by nearly two-fold at day 1 post-injection, passing from $70.8 \pm 7.4 \mathrm{Sox} 9^{+} \mathrm{C} 3^{+}$cells $/ \mathrm{mm}^{2}$ in the spinal cord white matter of PBS-injected mice to $129.1 \pm 5.6 \mathrm{Sox} 9^{+} \mathrm{C}^{+}$cells $/ \mathrm{mm}^{2}$ in animals that received $\mathrm{rmIL}-1 \mathrm{a}$ (Fig. $10 A-C)$. Next, we performed cell culture experiments using primary murine astrocytes and OLs to determine whether $\mathrm{OL}$ death is induced by toxic factors that are released from astrocytes upon IL-1a stimulation, rather than toxicity induced through cell-cell contact mediated mechanisms (Fig. 10D). Consistent with data discussed earlier that i.c.m. delivery of IL-1a to PdgfraCreER.::/17r $7^{r / r}$ mice did not lead to death of mature spinal cord OLs (Fig. 6), we found that the addition of rmIL-1a to the control medium was not toxic for OLs in vitro (Fig. 10E). However, the transfer of conditioned medium from IL-1astimulated astrocytes to cultured primary OLs was sufficient to evoke their death, as assessed using the LDH cytotoxicity assay. No significant cytotoxicity was detected on primary mature OLs when incubated with astrocyte-conditioned medium from untreated astrocytes. This indicates that IL-1a-stimulated astrocytes release factors that are lethal to mature OLs. Thus, we next aimed to determine the identity of the molecules that could harm OLs. Considering the susceptibility of OLs and neurons (axons) to reactive oxygen species (ROS) ${ }^{45,46}$, we hypothesized that ROS could be implicated in this cell death mechanism. To assess the potential involvement of ROS in cell death of mature spinal cord OLs, we first examined whether IL-1 a can trigger the production of ROS by astrocytes in vitro. For this, we cultured primary 
murine astrocytes in the presence of rmIL-1a or vehicle and then measured the production of ROS using the CellRox assay. We found that stimulation of astrocytes with IL-1a significantly increased the number ROS-producing cells (Fig 10F). We then attempted to validate this proposition in vivo using IL-1 a-injected C57BL/ 6 mice pretreated or not with N-acetyl-L-cysteine (NAC), a potent antagonist of ROS activity. Pretreatment with the NAC compound was sufficient to neutralize part of the effect of IL-1a on neutrophil infiltration (Suppl. Fig. 7A-C). More importantly, the NAC pretreatment completely prevented the loss of mature spinal cord OLs normally caused by central IL-1a administration (Fig 10G-I). Inhibition of ROS may therefore be a good target to mitigate inflammation and block secondary degeneration of mature OLs after SCl. We thus tested this hypothesis in a mouse model of contusion SCl. Although the NAC pretreatment failed to reduce neutrophil infiltration after SCI (Suppl. Fig. 7D-F), it did reduce the death of mature OLs caudal to the site of contusion injury when compared to saline-treated animals (Fig. 10J-L). This suggests, once more, that neutrophils are not the cause of $\mathrm{OL}$ cell death observed in mice injected i.c.m. with IL-1 $\mathrm{a}$ or those subjected to SCl. Together, these data show that IL-1 a activates astrocytes that in return release toxic ROS that contribute to secondary pathogenesis after SCI.

\section{Discussion}

It has long been recognized that the release of DAMPs initiate inflammation following tissue injury, but their identity and effects are only beginning to be understood in the injured CNS. Here, we investigated the role of the alarmin IL-1a in the context of SCl. We found that IL-1a is released by microglia located in the lesion core, most of which are dead as early as 24 hours post-SCI. Importantly, deletion of the I/1a or I/1r1 gene in mice not only reduced the infiltration of innate immune cells, but significantly diminished the death of mature OLs at sites of SCl. Delivery of IL-1a i.c.m. in an attempt to mimic SCI conditions triggered the recruitment and infiltration of neutrophils and led to a dramatic loss of mature OLs along the rostrocaudal axis of the spinal cord. Using sophisticated transgenic mouse lines in which we induced cell-specific restoration or deletion of the gene coding for IL-1R1 in CNS-resident cell populations, we found that OL cell death was indirectly mediated and involved both astrocytes and ECs. Last but not least, we uncovered that OL loss was caused by the release of ROS by IL-1a-stimulated reactive astrocytes.

IL-1a is a proinflammatory cytokine that contributes to inflammation in various disorders through activation of its cell-surface receptor IL-1R $1{ }^{47}$. In addition, IL-1a is ubiquitously expressed as a precursor protein of about $31 \mathrm{kDa}$ (pro-IL-1a) that is translocated from the cytoplasm to the cell nucleus under inflammatory conditions, where it acts as a proinflammatory activator of transcription ${ }^{48,49}$. Pro-IL-1a does not require proteolytic cleavage to be active ${ }^{50}$, despite the fact that proteolysis augments its biological potency ${ }^{51}$. Accordingly, the rapid release of IL-1 a from necrotic cells, but not apoptotic cells, following sterile injury to peripheral tissues makes it an ideal DAMP $38,52,53$. We recently reported that IL1a triggers neuroinflammation after $\mathrm{SCl}$, being produced by myeloid cells that either reside in or infiltrate the spinal cord from the bloodstream in response to the injury ${ }^{7}$. Taking advantage of Cre-inducible

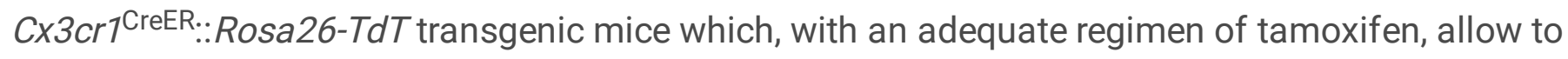


specifically label microglia but not monocyte-derived macrophages, we have extended these data to show that dead and damaged microglia are the main source of IL-1a in the early acute phase of SCl.

It is known that IL-1a can bind to at least three specific cell-surface receptors, namely IL-1R1, IL-1R2 and IL-1R3 ${ }^{41}$. However, the identity of the CNS resident cells that express each type of receptor has been hampered by the low in situ levels of the proteins and difficulties related to the purification of cell types purely. Although there is no doubt that IL-1R1 is strongly expressed by CNS ECs and some types of neurons, as shown by immunofluorescence microscopy ${ }^{13,37}$, the evidence supporting that microglia, astrocytes, OL lineage cells, and perivascular macrophages express IL-1 receptors has often been indirect and linked to the overall response of these cells to IL-1 treatment ${ }^{54-57}$. Here, the expression of IL-1R1 was analyzed by immunoblotting of membrane proteins extracted from specific primary cell cultures derived from the normal mouse brain. Our immunoblotting findings confirm that IL-1R1 is expressed by microglia, astrocytes and OLs, despite our failure to detect the IL-1R1 protein in these cells by way of immunofluorescence staining using paraformaldehyde (PFA)-fixed brain and spinal cord tissue sections. We interpret this to mean that IL-1R1 is weakly expressed in glial cells. Supporting this, Pinteaux et al. have previously reported that murine microglial cell cultures express low levels of IL-1R1 mRNA, but high levels of the decoy IL-1R2, conferring to these cells a high resistance to IL-1 cytokines ${ }^{58}$. This could explain why we failed to detect expression of the transcription factor Fos, a marker of cell activity, in microglia after central administration of IL-1a. In contrast, both astrocytes and mature OLs were activated throughout the mouse spinal cord as early as 1 hour post-injection, thus pointing towards those cells as potential direct or indirect targets of IL-1a.

We previously found that IL-1 a plays a critical role in SCI in mice. First, we showed that IL-1R1/MyD88 signaling is essential for the expression of CXCL1, CXCL2 and CCL2 chemokines by astrocytes and the subsequent recruitment of neutrophils and proinflammatory Ly $6 \mathrm{C}^{\text {hi }}$ monocytes at sites of $\mathrm{SCl}{ }^{59}$. Accordingly, deficiency in IL-1a led to a reduction in the infiltration of innate immune myeloid cells, reduced lesion volume and improved functional recovery after $\mathrm{SCl}$, effects that were correlated with an increased survival of mature $\mathrm{OLs}^{7}$. Until now, however, a direct causal effect relationship had yet to be demonstrated and the in vivo mechanisms underlying the effects of IL-1 a on OL loss remained obscure. Our novel findings shed light on these issues by revealing that IL- $1 \mathrm{a}$ by itself is sufficient to trigger a cascade of cellular and molecular events leading to the rapid death (within 24 hours) of nearly $40 \%$ of the population of mature OLs in the mouse spinal cord. Using a diphtheria toxin (DT) receptor-based strategy to selectively ablate mature OLs, Oluich et al. demonstrated that a loss of approximately $25 \%$ and $40 \%$ of mature OLs in the brain and spinal cord, respectively, resulted in severe clinical dysfunction with an ascending spastic paralysis ultimately leading to fatal respiratory impairment within 3 weeks of DT administration ${ }^{60}$. No evidence was found that OPCs compensate for the loss of mature OLs in that study. While two other groups also independently showed that genetically-induced death of mature OLs is associated with severe ataxia and tremor that correlates with signs of demyelination, impaired axonal conduction and even sometimes death, they found that surviving mice recovered from their neurological deficits and displayed OL replenishment and remyelination ${ }^{61,62}$. The replenishment of the OL population 
was determined to occur between 5 and 10 weeks following the toxin-mediated death of mature OLs, followed by complete attenuation of motor deficits by week $11^{61}$. Likewise, targeted laser-induced ablation of a single mature cortical OL resulted in the emergence of a newly matured $\mathrm{OL}$ within an approximate turnaround time of 11 weeks ${ }^{63}$. This prompted us to investigate in our model whether OPCs proliferate and differentiate to replace the original OLs and, if yes, what is the timing of this process. Strikingly, we found that the number of mature OLs came back to baseline after 3-5 days post-injection of IL-1a. BrdU pulse experiments and Ki67 immunostaining confirmed the proliferation of OPCs and their differentiation into newly matured Olig2 ${ }^{+} \mathrm{CC}^{+}{ }^{+} \mathrm{OLs}$. This rapid turnover is reminiscent of changes observed in the acutely injured spinal cord, where robust replacement of mature OLs by OPCs is taking place ${ }^{25,64}$. Although whether remyelination positively influences locomotor recovery after $\mathrm{SCl}$ remains a question of debate ${ }^{65}$, a better understanding of the mechanisms of replacement of lost OLs and myelin has a far more reach than the field of SCl alone. Collectively, these data suggest that $\mathrm{SCl}$ triggers a local response characterized by the release of alarmins, such as IL-1a, that induce the death of mature OLs and their rapid replacement by newly matured OLs, which are presumably more efficient at remyelinating the injured spinal cord.

We discovered that concomitant injection of IL-1a and anakinra, an IL-1 receptor antagonist, was sufficient to abolish the effects of IL-1 a on neutrophil infiltration and OL death. Accordingly, our data demonstrated that OLs were protected and functional recovery improved in $/ 11 \mathrm{a}^{-/-}$and $/ 11 \mathrm{r}^{-/-}$mice compared to WT mice after SCl. This prompted us to further investigate the mechanism behind IL-1amediated OL loss using various cell-specific IL-1R1 restored and knockout mouse lines. Our in vivo experiments revealed that the effects of IL-1a on neutrophils and mature OLs are indirect and mediated through activation of IL-1R1 signaling in CNS ECs and astrocytes. That endothelial IL-1R1, but not microglial IL-1R1, is necessary for mediating the central effects of IL-1ß on sickness behavior and leukocyte recruitment was recently proposed by the Quan laboratory ${ }^{66}$. Moreover, Liddelow and colleagues recently found that microglia-derived cytokines, including IL-1a, determine whether astrocytes will exert toxic or pro-survival effects on differentiated OLs (but not OPCs) and neurons in culture ${ }^{19}$. This implies that astrocytic IL-1R1 may contribute to some form of degeneration in variety of neurodegenerative diseases and CNS injuries. Under all activation conditions tested, microglia were found insufficient by themselves to induce neuronal death ${ }^{19}$. Whether microglia are protective or pathologic is also a matter of intense debate and most likely context-dependent. Depletion of microglia in mice injected i.c.m. with IL-1 a increased inflammation and OL loss, an effect that we associated to the overexpression of the decoy IL-1R2. In a mouse model of contusion SCl, microglia were proved to be a key cellular component of the scar that develops after $\mathrm{SCl}$ to protect neural tissue ${ }^{22}$. Using a mouse model of ischemic $\mathrm{SCl}$, neuroprotection conferred by repeated LPS treatment was partly reversed by specific deletion of microglial or endothelial IL-1R1 ${ }^{67}$. It is important to keep in mind, however, that Cre-reporter mouse lines have some limitations despite being a powerful tool to decipher molecular mechanisms in vivo. Perhaps the most important being that recombination in a specific cell type is often incomplete, which is particularly true in the case of tamoxifen-inducible CreER mice. This is especially limiting when

Page 14/44 
one aims to knockout a gene of interest, rather than restoring it, in a specific cell type in vivo. As the knockout will only be partial, it cannot be determined with certainty whether the response observed is due to the receptors that are still expressed by the targeted cell population or another cell type. Here, we circumvented part of this problem by using restored and knockout mouse models as well as primary cell lines, thus ensuring an additional level of confidence and reproducibility to our results. Therefore, it appears that IL-1 a released by spinal cord injured microglia triggers myeloid cell recruitment and secondary degeneration of OLs through IL-1R1 expressed by cells forming the neurovascular unit, namely ECs and astrocytes.

The role of astrocytes in $\mathrm{SCl}$, and more generally in CNS injury and diseases, has recently been a hot topic of discussion ${ }^{20}$. While some studies suggest that reactive astrocytes protect the injured spinal cord via their role in glial scar formation 21,68 , evidence suggests that they may also inhibit axonal regeneration and exacerbate secondary tissue damage ${ }^{69-72}$. The fact of the matter is that, pending the right conditions of activation and/or given the right molecular cues, astrocytes can adopt an axon growth-supporting phenotype despite their contribution to scar formation ${ }^{73}$. Overall, our results support the idea that astrocytes are plastic cells that adapt to their constantly changing microenvironment. When activated by IL-1a, we found that astrocytes produce and release ROS that in return induce death of mature OLs. Accordingly, treatment with the antioxidant NAC prevented the loss of OLs induced by either i.c.m. delivery of IL-1a or SCl in mice. That cells of the $\mathrm{OL}$ lineage are particularly vulnerable to oxidative damage after CNS injury has been suggested before ${ }^{74}$. Some studies reported improved functional recovery in NAC-treated rodents after traumatic brain or spinal cord injury ${ }^{75-77}$. Collectively, these findings suggest that IL-1a-activated astrocytes release toxic ROS that play a crucial role in secondary degeneration of OLs after SCl.

Recently, Liddelow et al. described a subtype of reactive astrocytes, termed A1 astrocytes, capable of inducing neurotoxicity by a still unknow mechanism ${ }^{19}$. More specifically, they found that the supernatant of astrocytes activated by a cocktail of microglia-derived proteins, namely IL-1a, TNF and C1q, was sufficient to induce cell death in primary cultures of neurons and mature OLs, but not OPCs or other CNS cell types. In an LPS model of systemic inflammation, each individual global knockout mouse line for either IL-1a, TNF or C1q showed a significant decrease in the A1 astrocytic response, but only the tripleknockout (II1 $\left.\mathrm{a}^{-/-} \mathrm{Tnf}^{--} \mathrm{C} 1 \mathrm{qa}^{-/}\right)$mice had no sign of astrocyte reactivity. Since TNF and C1q are also produced at sites of $\mathrm{SCl}$ during the early acute phase ${ }^{78,79}$, it is possible that the loss of mature OLS detected in our transgenic mouse models would have been further prevented by targeting these three genes at the same time. It will therefore be of interest in future work to validate the relevance of these immune molecules and their receptors, individually or in combination, in animal models of SCl using cellspecific conditional gene targeting strategies. Likewise, it will be important to identify other downstream effector molecules like ROS that directly mediate CNS cell toxicity.

In addition to reactive astrocytes, another possible source of ROS could be the innate immune cells that infiltrate the spinal cord during the early acute phase of SCl. Activated neutrophils have long been 
recognized to produce large amounts of ROS that, for example, increase vascular permeability and their subsequent infiltration of tissues ${ }^{80}$. Neutrophils have also been suspected to promote neurotoxicity through the release of ROS, TNF and proteases ${ }^{81}$. Of particular relevance here is the fact that neutrophils acquire neurotoxic properties following transmigration across IL-1-stimulated CNS endothelium ${ }^{82}$. Monocyte-derived proinflammatory (M1) macrophages should also be considered as another potential source of ROS in the injured spinal cord ${ }^{83}$. Like neutrophils, M1 macrophages were shown to be neurotoxic when co-cultured with primary neurons ${ }^{84}$. To answer the question of whether neutrophils and proinflammatory M1 monocytes have contributed to OL loss in response to central IL-1a delivery, we therefore had to turn to a depletion strategy that would deplete both types of myeloid cells simultaneously. Taking advantage of $L y 6 g^{\text {Cre-TdT }}$ mice, Faget et al. recently showed that both neutrophils and proinflammatory M1 monocytes can be efficiently depleted by repeated injections of anti-Gr-1 (Ly6C/G) antibodies, clone RB6-8C5, but not anti-Ly6G (1A8) antibodies ${ }^{85}$, a finding that we confirmed here both in blood and $\mathrm{SCl}$ tissue. Another key new finding of our study is that neutrophils and proinflammatory M1 monocytes are not implicated in the OL loss observed after i.c.m. injection of IL-1a.

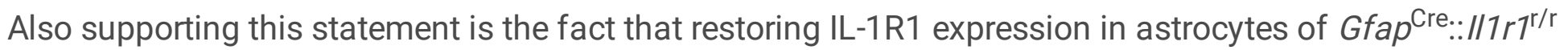
mice did not restore the infiltration of neutrophils in response to IL-1a, yet restored OL cell death near to WT levels. Taken together with our previous work, this study suggests that endothelial IL-1R1 is required for neutrophil recruitment in the spinal cord under sterile inflammatory conditions, but that these innate immune cells do not contribute to OL loss during neuroinflammation. Instead, astrocytes and CNS ECs appear to drive OL cell death via an IL-1R1-dependent release of ROS and other yet to be identified molecules.

In summary, our results show that the alarmin IL-1a released by damaged microglia drives neuroinflammation and $\mathrm{OL}$ loss after $\mathrm{SCl}$. These responses are mediated in part through activation of endothelial and astrocytic IL-1R1 signaling, the end result of which is the release of toxic ROS. Thus, IL-1a inhibition may prove to be a valuable strategy to prevent secondary degeneration after $\mathrm{SCl}$.

\section{Materials And Methods}

\section{Mice}

A total of 433 mice of either sex were used in this study. Male and/or female C57BL/ 6 mice were purchased from Charles River Laboratories or The Jackson Laboratory (JAX) at 8-10 weeks of age. $C \times 3 c r 7^{\text {CreER }}$ mice were obtained from the European Mouse Mutant Archive, with prior authorization from Dr. Steffen Jung (Rehovot, Israel), and genotyped as described ${ }^{86}$. Breeders for Rosa26-tdTomato (also known as Ai9, stock \#007905, ${ }^{87}$ ), Pdgfra ${ }^{\text {CreER }}$ (stock \#018280, ${ }^{88}$ ), Gfap ${ }^{\text {Cre }}$ (stock \#024098, ${ }^{89}$ ), and

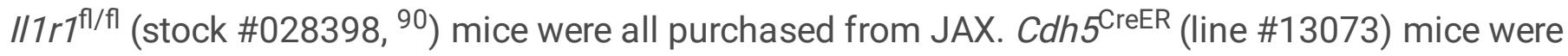
obtained from the Cancer Research Technology Repository at Taconic, with prior consent of the creator of the mouse line ${ }^{91}$, Dr. Ralf Adams (London Research Institute, UK). $/ / 1 r 7^{r / r}$ mice were obtained from Dr. Ning Quan ${ }^{42}$. Cx3 $c 7^{\text {CreER }}$, Pdgfra ${ }^{\mathrm{CreER}}$, Gfap $^{\mathrm{Cre}}$ and $\mathrm{Cdh} 5^{\mathrm{CreER}}$ mice were bred in-house and crossed with 
either Rosa26-tdTomato (R26-TdT), $/ 11 r 7^{r / r}$ or $/ / 1 r 7^{f / f l}$ mice at the Animal Facility of the Centre de recherche du Centre hospitalier universitaire ( $\mathrm{CRCHU}$ ) de Québec-Université Laval. Wild-type littermates generated from heterozygous matings were used as controls. Mice had free access to food and water at all time. All animal procedures were approved by the Université Laval Animal Care Committee and conducted in compliance with relevant ethical regulations and guidelines of the Canadian Council on Animal Care.

\section{Tamoxifen treatment}

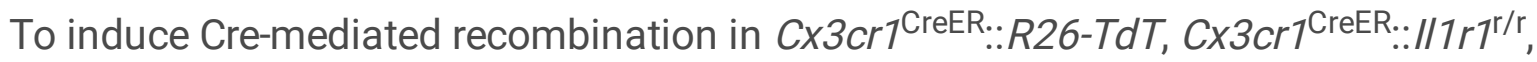

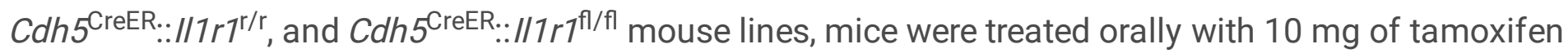
(dissolved in 1:10 ethanol/corn oil) twice at 2-day intervals starting at postnatal day (P) 30-32. To induce recombination in PdgfraCreER.::/11 r $7^{\mathrm{r} / \mathrm{r}}$ mice, animals were treated intraperitoneally with $2 \mathrm{mg}$ of tamoxifen twice at 2-day intervals starting at P12-14.

\section{Spinal cord injury (SCl)}

Mice were anesthetized with isoflurane and underwent a laminectomy at vertebral level T9-10, which corresponds to spinal segment T10-11. Briefly, the vertebral column was stabilized and a contusion of 50 kdyn was performed using the Infinite Horizon SCI device (Precision Systems \& Instrumentation). Overlying muscular layers were then sutured and cutaneous layers stapled. Post-operatively, animals received manual bladder evacuation twice daily to prevent urinary tract infections.

\section{Behavioral analysis}

Recovery of locomotor function after $\mathrm{SCl}$ was quantified in an open field using the BMS, according to the method developed by Basso and colleagues ${ }^{92}$. All groups of mice exhibited similar parameters in terms of the impact force and spinal cord tissue displacement prior to BMS testing. All behavioral analyses were done blind with respect to the identity of the animals.

\section{Intra-cisterna magna injections}

Mice were injected i.c.m. with either rmIL-1a (doses ranging from 20 to $100 \mathrm{ng} / \mu \mathrm{L}$ diluted in PBS, $5 \mu \mathrm{L}$ injected per mouse, Peprotech catalog \#211-11A), rmIL-1b (20 to $100 \mathrm{ng} / \mu \mathrm{L}$ diluted in PBS, $5 \mu \mathrm{L} / \mathrm{mouse}$, Peprotech catalog \#211-11B), anakinra (also known as Kineret ${ }^{\circledR}, 100 \mu \mathrm{g} / \mu \mathrm{L}, 5 \mu \mathrm{L} / \mathrm{mouse}$ ) or PBS (5 $\mu \mathrm{L} /$ mouse). The i.c.m treatment consisted of a single injection using a pulled-glass micropipette connected to a $10-\mu \mathrm{L}$ Hamilton syringe.

\section{Bromodeoxyridine injections}

To label proliferating cells, mice were intraperitoneally injected once daily with $\mathrm{BrdU}$ ( $50 \mathrm{mg} / \mathrm{kg}$ of body weight in $0.9 \%$ saline) for 3 consecutive days, starting on day 1 post-i.c.m. injection of either IL-1a or PBS. 


\section{Microglia depletion}

To eliminate microglia, mice were fed PLX-5622, a CSF1R inhibitor provided by Plexxikon and formulated at a dose of $1200 \mathrm{mg} / \mathrm{kg}$ in AIN-76A chow from Research Diets Inc., for 21 consecutive days.

\section{Myeloid cell depletion}

Neutrophils and monocytes were depleted through repeated i.p. injections of anti-mouse Ly6C/Ly6G antibody, clone RB6-8C5, purchased from BioXCell. Rat IgG2a isotype (clone 2A3; BioXCell) and PBS served as controls. Mice were injected with $100 \mu \mathrm{l}$ of antibody at $0.2 \mu \mathrm{g} / \mu \mathrm{l}$ or PBS at 1 and 2 days prior to and immediately after central IL-1a administration.

\section{In vivo inhibition of ROS production}

Mice received 4 injections of saline or NAC $(150 \mathrm{mg} / \mathrm{kg})$ intraperitoneally at 12 hours before, 1 hour before, 12 hours after and 24 hours after i.c.m injection of either PBS or rmIL-1a.

\section{Tissue processing}

Mice were overdosed with a mixture of ketamine $(400 \mathrm{mg} / \mathrm{kg})$ and xylazine $(40 \mathrm{mg} / \mathrm{kg})$ and transcardiacally perfused with 1\% PFA, pH 7.4, in PBS. Spinal cords were dissected out from vertebral columns, post-fixed for an additional 48 hours in $1 \%$ PFA at $4^{\circ} \mathrm{C}$, and then transferred into PBS $+20 \%$ sucrose for at least 24 hours before tissue sectioning. Spinal cords were then blocked into $4-\mathrm{mm}$ segments, corresponding to the upper cervical, mid-thoracic and upper lumbar levels. Therefore, for each animal, a total of three spinal cord segments were embedded in Shandon ${ }^{T M} \mathrm{M}-1$ Embedding Matrix (Thermo Fisher Scientific) and tissue sections cut at a thickness of $14 \mu \mathrm{m}$ using a cryostat (model CM3050S; Leica Biosystems). All sections were collected directly onto Surgipath X-tra ${ }^{\circledR}$ slides having a permanent positive charged surface (Leica Microsystems Canada) and stored at $-20^{\circ} \mathrm{C}$ until use.

\section{Immunostaining and quantification}

Immunofluorescence labeling was performed according to our previously published method ${ }^{79}$. Primary antibodies used in this study are of the following sources (catalog numbers in parentheses) and were used at the indicated dilutions: rat anti-BrdU (1:750, Abcam, ab6326), rat anti-C3 (1:100, Abcam, ab11862), mouse anti-CC1 (1:500, Abcam, ab16794), rat anti-CD11b (1:250, AbD Serotec, MCA711), rabbit anti-Fos (1:500, Cell signaling, \#2250), mouse anti-GalC (1:800, Millipore, MAB342), goat anti-lba1 (1:1500, Novus Biologicals, NB100-1028), goat anti-IL-1 a (1:100 dilution, R\&D Systems, AF-400-NA), rabbit anti-Ki67 (1:200, Abcam, ab15580), rabbit anti-laminin (1:1000, Dako, Z0097), rat anti-Ly6G (1:2000, BD Biosciences, \#551459), rat anti-NG2 (1:200, R\&D Systems, MAB6689), mouse anti-04 (1:400, R\&D Systems, MAB1326), goat anti-Olig2 (1:400, R\&D Systems, AF2418), rabbit anti-P2ry12 (1:500, AnaSpec, AS-55043A), goat anti-Sox9 (1:250, R\&D Systems, AF3075), and rabbit anti-Sox9 (1:1000, Millipore, AB5535). For Ki67 immunofluorescence, antigen retrieval was performed using sodium citrate buffer at $95^{\circ} \mathrm{C}$ for $5 \mathrm{~min}$. For BrdU, tissue sections were treated with $\mathrm{HCl}(2.0 \mathrm{~N})$ for 30 min at $37^{\circ} \mathrm{C}$ 
followed by $0.1 \mathrm{M}$ sodium borate $(\mathrm{pH} 8.5)$ for $10 \mathrm{~min}$ at room temperature. Primary antibodies were visualized with appropriate Alexa Fluor ${ }^{\circledR}$-conjugated secondary antibodies from Thermo Fisher Scientific (1:250 dilution). DAPI ( $1 \mu \mathrm{g} / \mathrm{ml}$, Thermo Fisher Scientific) was used for nuclear counterstaining. Sections were imaged on a Zeiss LSM 800 confocal microscope system equipped with 405, 488, 561, and 640nm lasers. Confocal images were acquired using a Zeiss Axiocam 506 Mono camera and mosaics created using the Zen 2.3 software (Blue edition).

All stereological counts were performed using the BIOQUANT Life Science software (v. 18.5, Bioquant Image Analysis Corporation). For the quantification of activated glial cells $\left(\mathrm{Fos}^{+} \mathrm{Olig} 2^{+}\right.$or $\mathrm{Fos}^{+} \mathrm{Sox}^{+}$), OLs (Olig2 ${ }^{+} \mathrm{CC}^{+}$or Olig2 ${ }^{+} \mathrm{BrdU}^{+}$or Olig $2^{+} \mathrm{Ki} 67^{+}$) and reactive inflammatory astrocytes $\left(\mathrm{Sox} 9^{+} \mathrm{C}^{+}\right.$), the total number of immunolabeled cells in the spinal cord white matter per cross section was counted at 20', $40^{\prime}$ and $20^{\prime}$ magnification, respectively. For the quantification of neutrophils, the total number of $\mathrm{Ly}^{\prime} \mathrm{G}^{+}$ cells into the spinal cord blood vessels or parenchyma, delineated using pan-laminin immunostaining, was counted at $20^{\prime}$ magnification in the entire spinal cord cross section. Only immunolabeled cells with a DAPI-stained nucleus were counted and results presented as the total number of immunolabeled cells per $\mathrm{mm}^{2}$. All quantifications were done blind with respect to the identity of the animals.

\section{Isolation of specific CNS cell types}

OPCs and late OL progenitors (pro-OLs): OPCs were isolated from the neonatal (P7-P9) mouse brain to perform cell culture studies, whereas pro-OLs were isolated from adult brains (6-8 weeks old mice) to assess the efficiency of Cre-mediated recombination. Mouse pups were anesthetized on ice and sacrificed by decapitation according to institutional guidelines. Adult mice were anesthetized and perfused intracardially with ice cold Hanks' balanced salt solution (HBSS) without $\mathrm{Ca}^{2+} / \mathrm{Mg}^{2+}$ to remove blood from the vasculature. Brains were extracted and cerebral cortices dissected and diced into small pieces, which were then incubated in a mixture of papain $(0.9 \mathrm{mg} / \mathrm{mL})$, cysteine $(0.2 \mathrm{mg} / \mathrm{mL})$ and DNase I $(39 \mathrm{U} / \mathrm{ml})$ at $37^{\circ} \mathrm{C}$ for $20 \mathrm{~min}$ on an orbital shaker. The digestion was stopped by adding trypsin inhibitor to a final concentration of $5 \mathrm{mg} / \mathrm{mL}$, and tissue dissociated into a single-cell suspension by gentle mechanical trituration. OPCs and pro-OLs were isolated by immunopanning at room temperature using antibodies directed against PDGFRa (CD140a) and 04 cell surface markers, respectively, following the methods of Emery and Dugas ${ }^{93}$.

Microglia: Microglia were isolated from the adult mouse spinal cord at 8 weeks of age to determine the efficiency of Cre-mediated recombination or to assess gene expression by qRT-PCR. In brief, mice were transcardially perfused with cold HBSS (without $\mathrm{Ca}^{2+} / \mathrm{Mg}^{2+}$ ) to remove immune cells from the vasculature, their spinal cords dissected out and gently mechanically homogenized on ice. Cells were next filtered through a 70- $\mu$ m nylon mesh cell strainer (BD Biosciences), fractionated using $37-70 \%$ Percoll density gradient centrifugation and microglia-enriched fractions purified by cell sorting according to the methods and cell surface markers described below. 
Endothelial cells (ECs): ECs were isolated from brain capillaries of 6-8 weeks old mice. In brief, mouse brain tissue, free of meninges, was minced, homogenized and digested in a mixture of $0.7 \mathrm{mg} / \mathrm{ml}$ collagenase type II and $39 \mathrm{U} / \mathrm{ml}$ DNase I in DMEM for $75 \mathrm{~min}$ at $37^{\circ} \mathrm{C}$. Myelin was removed by centrifugation at $1,000 \mathrm{~g}$ for $20 \mathrm{~min}$ in $20 \%$ BSA-DMEM. The cell pellet was then incubated for another hour at $37^{\circ} \mathrm{C}$ with a mixture of $1 \mathrm{mg} / \mathrm{ml}$ collagenase-dispase and $39 \mathrm{U} / \mathrm{ml}$ DNAse I in DMEM. Microvascular ECs were separated on a $33 \%$ continuous Percoll gradient.

Astrocytes: Astrocytes were isolated from the cortex of P0-P2 mouse pups, as described by Schildge and colleagues ${ }^{94}$. In brief, meninges were removed and cortex isolated, minced and incubated for 40 minutes in a collagenase IV solution $(750 \mathrm{U} / \mathrm{mL})$ at $37^{\circ} \mathrm{C}$ under occasional agitation. The suspension was centrifuged, resuspended in complete DMEM supplemented with $10 \%$ FBS, dissociated into a single-cellsuspension and then seeded in $\mathrm{T} 75$ flasks coated with poly-D-lysine in a $37^{\circ} \mathrm{C}, 5 \% \mathrm{CO} 2$ humidified incubator. After 7-8 days, cells were agitated on an orbital shaker at $37^{\circ} \mathrm{C}$ at $180 \mathrm{rpm}$ for $30 \mathrm{~min}$ to remove microglia. Medium was removed and replaced by fresh medium. Cells were again agitated at $37^{\circ} \mathrm{C}$ at 240 rpm for 6 hours to remove OPCs. Medium was removed and astrocytes were collected by trypsinization.

\section{Primary cell culture}

Oligodendrocytes: OPCs were seeded in poly-L-lysine-coated cell culture plates in the presence of DMEMSato Base Growth Medium and their proliferation induced by adding platelet-derived growth factor-AA (PDGF-AA, $10 \mathrm{ng} / \mathrm{mL}$ ) and basic fibroblast growth factor (bFGF, $20 \mathrm{ng} / \mathrm{mL}$ ) in the absence of the T3 thyroid hormone, following a protocol adapted from Haines and colleagues ${ }^{95}$. Once in sufficient numbers, OPCs were differentiated into mature OLs by adding the T3 hormone to the DMEM-Sato Base Growth Medium, in the absence of PDGF and bFGF. The differentiation of OPCs into mature OLs was confirmed by immunostaining against the 04 marker and assessed according to cell morphology.

Endothelial cells: Primary brain microvascular endothelial cells (BMECs) were plated on culture dishes coated with $10 \mu \mathrm{g} / \mathrm{ml}$ collagen type IV and $5 \mathrm{mg} / \mathrm{ml}$ gelatin and cultured in DMEM supplemented with $20 \% \mathrm{FBS}, 1 \mathrm{ng} / \mathrm{mL}$ basic fibroblast growth factor, $100 \mu \mathrm{g} / \mathrm{mL}$ heparin, $1.4 \mu \mathrm{M}$ hydrocortisone with antibiotics and antimycotics. Medium was supplemented with puromycin $(10 \mu \mathrm{g} / \mathrm{mL})$ for the first 2 days of culture, after which the concentration was adjusted to $4 \mu \mathrm{g} / \mathrm{mL}$.

Astrocytes: Primary cultures of mouse astrocytes were prepared from the cortex of P0-P2 pups, as described above, and used from passages 3 to 4 . Cells were grown in complete Dulbecco's Modified Eagle Medium (DMEM) either in 6-well plates (to generate astrocytes-conditioned medium, ACM) or directly into 96-well plates (for the ROS assay) coated with poly-L-lysine $(0.1 \mathrm{mg} / \mathrm{ml}$ ) at a density of 200,000 cells/well or 20,000 cells/well, respectively.

\section{Automated blood cell count, flow cytometry and cell sorting}

Mice were overdosed with a mixture of ketamine-xylazine and their blood collected via cardiac puncture using a 22-gauge heparinized syringe. Blood samples were immediately transferred into EDTA-coated 
microtubes (Sarstedt) and put on slow rotation at $5 \mathrm{rpm}$ (using the Mini LabRoller ${ }^{\mathrm{TM}}$ Rotator) until processing. Automated complete blood cell count was performed using the Scil Vet abc Plus ${ }^{\mathrm{TM}}{ }^{\mathrm{T}}$ Analyzer (Scil Animal Care Company), following manufacturer's instructions. For flow cytometry, red blood cells were lysed and the remaining cells incubated with Mouse Fc Block (i.e., purified anti-mouse CD16/CD32; BD Biosciences) for 15 minutes at $4^{\circ} \mathrm{C}$ to prevent nonspecific binding. Multicolor labeling was then performed using the LIVE/DEAD ${ }^{\text {TM }}$ Fixable Yellow Dead Cell Stain Kit (Thermo Fisher Scientific) and the following fluorescently-conjugated primary antibodies: PerCP-conjugated anti-CD45 (1:50 dilution), Alexa 700-conjugated anti-CD11b (1:50), BD HorizonTM V450-conjugated anti-Ly6C (1:83), and PE-Cy7conjugated anti-Ly6G (1:50) (all from BD Biosciences). Cells were analyzed using FlowJo software (v. 9.2; Tree Star Inc.) on a FACS LSRII flow cytometer (BD Biosciences).

For the purification of microglia needed for DNA and mRNA analyses by means of quantitative real-time PCR (qPCR) and RT-PCR (qRT-PCR), respectively, microglia were isolated from the adult spinal cord as described above and then sorted using a BD FACSAria II (BD Biosciences). The following primary antibodies were used: PerCP-conjugated anti-CD45 (1:50 dilution), Alexa 700-conjugated anti-CD11b (1:50), FITC-conjugated anti-Ly6C (1:83), and PE-Cy7-conjugated anti-Ly6G (1:50) (all from BD Biosciences). Microglia were identified as CD45 ${ }^{\text {int }} \mathrm{CD} 11 \mathrm{~b}^{+}$Ly6C $\mathrm{C}^{-}$Ly6G $\mathrm{G}^{-}$cells.

\section{Assessment of Cre-mediated recombination using qPCR}

Genomic DNA was extracted from pro-OLs, microglia, ECs or astrocytes isolated from the mouse CNS using the GenElute Mammalian Genomic DNA Miniprep Kit (Sigma-Aldrich Canada Ltd.), according to the manufacturer's instructions. The following primers were used to determine the extent of Cre-mediated deletion of the inserted sequence, which contained a neocassette ( $\mathrm{Neo}$ ) and other interfering elements (flanked by loxP sites) causing disruption of $/ 11 r 1$ gene expression, and whose deletion restored the normal coding frame of the $/ / 1 r 1$ gene in $/ / 1 r r^{1 / r}$ mice crossed with cell-specific Cre mice: Neo, $5^{\prime}$ gcttgggtggagaggctattc-3' and 5'-gcctcgtcttgcagttcattca-3' and I/1r1 (intron 7), 5'gcccttttcttacattctatttggtgc-3' and 5'-caagaaggagttaaccgggacatc-3'. Primers designed to amplify intron 7 of the $/ 11 r 1$ gene were used to normalize gene expression between animals, and data expressed as fold change relative to the WT group. To determine the extent of deletion of the floxed $/ / 1 \mathrm{r} 1$ alleles in

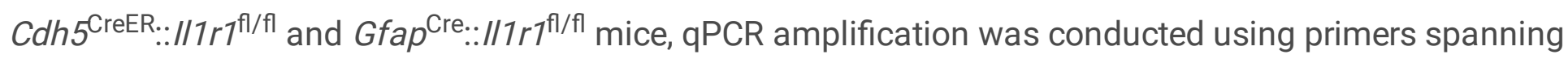
intron 2 and exon 3 of the I/1r1 gene: //1r1 (intron 2-exon 3), 5'-cattgcttctcctttctctcttttaa-3' and 5'gccgtgcattttatttggagta-3'. As above, intron 7 was amplified to normalize data. The sequences chosen were selected to match only the intended gene using the GeneTool software (v. 2.0, BioTools Inc.), and verified by BLAST analysis in GenBank. Amplification was performed using reagents of the KAPA SYBR ${ }^{\circledR}$ FAST qPCR Master Mix Kit (Kapa Biosystems Ltd.) optimized for the LightCycler 480 (Roche Diagnostics), and by following these conditions for PCR reactions: 45 cycles, denaturation at $95^{\circ} \mathrm{C}$ for 30 sec, annealing/elongation and reading at either $62^{\circ} \mathrm{C}$ (for amplification of the Neo sequence) or $58^{\circ} \mathrm{C}$ (intron 2-exon 3 of the mouse $/ 11 \mathrm{r} 1 \mathrm{gene}$ ) for $30 \mathrm{sec}$. A melting curve was performed to assess nonspecific signal. Relative quantity was calculated using the delta Ct method. Quantitative real-time PCR 
measurements were performed by the CRCHU de Québec-Université Laval Gene Expression Platform and were compliant with MIQE guidelines.

\section{Assessment of gene expression using real time qRT-PCR}

FACS-isolated spinal cord microglia were homogenized using Qiazol Lysis Reagent (Qiagen) and total RNA extracted using the miRNeasy Micro Kit On-column DNase (Qiagen), following the manufacturer's instructions. The quantity of total RNA was measured using a NanoDrop ND-1000 Spectrophotometer (NanoDrop Technologies). First-strand cDNA synthesis was accomplished using 0.1-0.2 $\mu \mathrm{g}$ of isolated RNA in a reaction containing $200 \mathrm{U}$ of Superscript IV RNase H-RT (Thermo Fisher Scientific), $300 \mathrm{ng}$ of oligo-dT ${ }_{18}, 50 \mathrm{ng}$ of random hexamers, $50 \mathrm{mM}$ Tris- $\mathrm{HCl}$ pH 8.3, $75 \mathrm{mM} \mathrm{KCl}, 3 \mathrm{mM} \mathrm{MgCl} 2,500 \mu \mathrm{M}$ deoxynucleotides triphosphate, $5 \mathrm{mM}$ dithiothreitol, and $40 \mathrm{U}$ of Protector RNase Inhibitor (Roche Diagnostics) in a final volume of $50 \mu \mathrm{l}$. The reaction was incubated at $25^{\circ} \mathrm{C}$ for $10 \mathrm{~min}$ and then at $50^{\circ} \mathrm{C}$ for $20 \mathrm{~min}$, followed by inactivation by incubation at $80^{\circ} \mathrm{C}$ for $10 \mathrm{~min}$. A PCR Purification Kit (Qiagen) was used to purify cDNA. cDNA corresponding to $10-18 \mathrm{ng}$ of total RNA was used to perform fluorescentbased real-time PCR quantification using the LightCycler 480 (Roche Diagnostics). Reagents of the KAPA SYBR ${ }^{\circledR}$ FAST qPCR Master Mix Kit (Kapa Biosystems Ltd.) optimized for the LightCycler 480 were used as described by the manufacturer. The primer pairs were: //1r2, 5'-gagaccccacacgcctattga-3' and 5'ggttccgtggttgttcctttga-3' and Gapdh, 5'-ggctgcccagaacatcatccct-3' and 5'-atgcctgcttcaccaccttcttg-3'. Once again, primer pairs were designed using the GeneTool 2.0 software (Biotools Inc.) and their specificity verified by blast in the GenBank database. The conditions for PCR reactions were: 45 cycles, denaturation at $95^{\circ} \mathrm{C}$ for $30 \mathrm{sec}$, annealing/elongation and reading at $60^{\circ} \mathrm{C}$ for $30 \mathrm{sec}$. A melting curve was performed to assess non-specific signal. Relative quantity was calculated using the delta $\mathrm{Ct}$ method. Normalization was performed with the delta-delta Ct method using the PBS group and the Gapdh gene used as a reference. Real time qRT-PCR measurements were performed by the CRCHU de Québec-Université Laval Gene Expression Platform and were compliant with MIQE guidelines.

\section{Immunoblotting analysis}

For protein extraction, cells were washed twice with ice cold PBS and then incubated in ice cold RIPA lysis buffer ( $100 \mu \mathrm{L}$ for $1^{\prime} 10^{6}$ cells; $20 \mathrm{mM}$ Tris-HCl pH 8.0, 2 mM EDTA, 10 mM EGTA, 1\% Triton X-100) containing Protease and Phosphatase Inhibitor Cocktail (Sigma-Aldrich Canada Ltd.). Cells were scraped off the plate and the lysate immediately transferred to a microcentrifuge tube on ice. Homogenates were sonicated and incubated for $20 \mathrm{~min}$ at $4^{\circ} \mathrm{C}$ under rotation to complete cell lysis. Tubes were centrifuged at $13,000 \mathrm{~g}$ for $20 \mathrm{~min}$ at $4^{\circ} \mathrm{C}$ and supernatant collected into new microtubes. Protein levels were determined using the BCA Protein Assay Kit (Sigma-Aldrich Canada Ltd.).

For quantification of protein levels, 3 to $10 \mu \mathrm{g}$ of proteins were boiled and electrophoresed on SDSacrylamide gel, followed by blotting on PVDF or nitrocellulose membranes (PerkinElmer). Membranes were blocked for 1 hour with 5\% dry milk in TBST buffer ( $50 \mathrm{mM}$ Tris- $\mathrm{HCl} \mathrm{pH} \mathrm{8.0,150} \mathrm{mM} \mathrm{NaCl}, 0.05 \%$ Tween-20) and then incubated overnight in 5\% milk/TBST solution containing primary antibody. The 
following antibodies were used: mouse anti-actin (1:75000, EMD Millipore, MAB1501), rabbit anti-GFAP (1:8000, Agilent Technologies (Dako), Z0334), and goat anti-IL-1R1 (1:1500, R\&D Systems, AF-771).

Membranes were incubated with secondary antibodies conjugated to horseradish peroxidase (1:2500, Vector Laboratories) and cross-reactive bands visualized by chemiluminescence (PerkinElmer).

\section{Detection of ROS in vitro}

Production of ROS was assessed in living cells by using the fluorogenic probe CellROX® Green Reagent (Thermo Fisher Scientific), a cell-permeable dye that is non-fluorescent while in a reduced state but upon oxidation exhibits strong fluorescent signal with excitation/emission maxima of $\sim 485 / 520 \mathrm{~nm}$. Primary astrocytes, seeded in 96-well plates at 20,000 cells/well, were exposed to vehicle or rmlL-1a $(10 \mathrm{ng} / \mathrm{mL})$ for $24 \mathrm{~h}$. Cells were loaded with $5 \mu \mathrm{M}$ CellROX® Green Reagent and $1 \mu \mathrm{g} / \mathrm{ml}$ Hoechst 33342, for nuclear counterstain, for 30 min and then rinsed three times with PBS and finally fixed with PFA 4\% for 15 minutes at room temperature. Imaging was then performed using the EVOS ${ }^{\circledR}$ FL Auto Imaging System (Thermo Fisher Scientific) and further analysed with Image J.

\section{In vitro cytotoxic assay}

To study the effect of conditioned medium derived from astrocytes or ECs stimulated with either IL-1a or PBS on the survival of mature OLs, cell viability was measured using the Pierce Lactate Dehydrogenase (LDH) Cytotoxicity Assay Kit (Thermo Fisher Scientific), according to the manufacturer's instructions. In brief, primary astrocytes were plated in 6-well plates at a density of 100,000 cells/well and treated with either $\mathrm{rmLL}-1 \mathrm{a}(10 \mathrm{ng} / \mathrm{mL})$ or PBS. Following a 24-hour incubation period, the conditioned medium was removed and immediately transferred onto mature OLs plated at a density of 20,000 cells/well in 96-well plates for 24 hours. The LDH reaction mixture was then added to the culture medium for 30 minutes at room temperature, the reactions stopped and absorbances measured at $490 \mathrm{~nm}$ and $680 \mathrm{~nm}$ (background signal from the instrument) using the SpectraMax i3 (Molecular Devices).

\section{Statistical analysis}

Statistical evaluations were performed using one- or two-way ANOVA or repeated-measures ANOVA where appropriate. The multiple comparisons adjustment was made using the Bonferroni correction. All statistical analyses were performed using the GraphPad Prism software (v.7, GraphPad Software Inc.). A $p$ value $<0.05$ was considered as statistically significant. All data in graphs are expressed as means \pm SEM.

\section{Declarations}

\section{ACKNOWLEDGMENTS}

This study was supported by grants from the Canadian Institutes of Health Research (PJT-168852 to S.L.) and Natural Sciences and Engineering Research Council of Canada (RGPIN-2015-05281 to S.L.). This project has also been made possible with the financial support of Health Canada, through the Canada 
Brain Research Fund, an innovative partnership between the Government of Canada (through Health Canada) and Brain Canada, and the Barbara Turnbull Foundation for Spinal Cord Research. Salary support to F. B. was in part provided by the Fondation du CHU de Québec and the Centre thématique de recherche en neurosciences (CTRN). We thank Nadia Fortin for her invaluable technical assistance. This manuscript is dedicated to the memory of our friends and colleagues Giamal N. Luheshi and Guy Drolet, who sadly passed away in 2020 .

\section{AUTHOR CONTRIBUTIONS}

F.B. conceived the study, designed and performed most of the experiments, analyzed the data, drafted the figures and wrote the manuscript. A.C.M., M.K., D.B. and M.L. performed immunofluorescence and quantitative analyses, some in vitro experiments, as well as commented on the manuscript. B.M. participated to the experimental design and commented on the manuscript. N.V. acquired microscopy images and edited all figures. X.L. and N.Q. provided materials and commented on the manuscript. S.L. conceived the study, designed the experiments, supervised the overall project and wrote the manuscript.

\section{References}

1 Tator, C. H. \& Fehlings, M. G. Review of the secondary injury theory of acute spinal cord trauma with emphasis on vascular mechanisms. J Neurosurg 75, 15-26., (1991).

2 Tator, C. H. Update on the pathophysiology and pathology of acute spinal cord injury. Brain Patho/ 5, 407-413., (1995).

3 David, S. \& Lacroix, S. in Clinical Neuroimmunology (eds J. Antel, G. Birnbaum, H. P. Hartung, \& A. Vincent) 53-63 (Oxford University press, 2005).

4 Nimmerjahn, A., Kirchhoff, F. \& Helmchen, F. Resting microglial cells are highly dynamic surveillants of brain parenchyma in vivo. Science $\mathbf{3 0 8}, 1314-1318,(2005)$.

5 Davalos, D. et al. ATP mediates rapid microglial response to local brain injury in vivo. Nat Neurosci 8 , 752-758, (2005).

6 de Rivero Vaccari, J. P. et al. P2X4 receptors influence inflammasome activation following spinal cord injury. J Neurosci 32, 3058-3066, (2012).

7 Bastien, D. et al. IL-1alpha gene deletion protects oligodendrocytes after spinal cord injury through upregulation of the survival factor Tox3. J Neurosci 35, 10715-10730, (2015).

8 Gadani, S. P., Walsh, J. T., Smirnov, I., Zheng, J. \& Kipnis, J. The glia-derived alarmin IL-33 orchestrates the immune response and promotes recovery following CNS injury. Neuron $\mathbf{8 5}, \mathbf{7 0 3 - 7 0 9 , ( 2 0 1 5 ) .}$

9 Kigerl, K. A., Lai, W., Wallace, L. M., Yang, H. \& Popovich, P. G. High mobility group box-1 (HMGB1) is increased in injured mouse spinal cord and can elicit neurotoxic inflammation. Brain Behav Immun 72, 
22-33, (2018).

10 Ericsson, A., Liu, C., Hart, R. P. \& Sawchenko, P. E. Type 1 interleukin-1 receptor in the rat brain: distribution, regulation, and relationship to sites of IL-1-induced cellular activation. J Comp Neuro/361, 681-698, (1995).

11 Nadeau, S. \& Rivest, S. Effects of circulating tumor necrosis factor on the neuronal activity and expression of the genes encoding the tumor necrosis factor receptors (p55 and p75) in the rat brain: a view from the blood-brain barrier. Neuroscience 93, 1449-1464, (1999).

12 McCandless, E. E. et al. IL-1R signaling within the central nervous system regulates CXCL12 expression at the blood-brain barrier and disease severity during experimental autoimmune encephalomyelitis. J Immuno/ 183, 613-620, (2009).

13 Levesque, S. A. et al. Myeloid cell transmigration across the CNS vasculature triggers IL-1beta-driven neuroinflammation during autoimmune encephalomyelitis in mice. J Exp Med 213, 929-949, (2016).

14 Li, Q. et al. Endothelial IL-1R1 is a critical mediator of EAE pathogenesis. Brain Behav Immun 25, 160167, (2011).

15 Pare, A. et al. IL-1beta enables CNS access to CCR2(hi) monocytes and the generation of pathogenic cells through GM-CSF released by CNS endothelial cells. Proc Natl Acad Sci U S A 115, E1194-E1203, (2018).

16 Proebstl, D. et al. Pericytes support neutrophil subendothelial cell crawling and breaching of venular walls in vivo. J Exp Med 209, 1219-1234, (2012).

17 Zhu, W. et al. Interleukin receptor activates a MYD88-ARNO-ARF6 cascade to disrupt vascular stability. Nature 492, 252-255, (2012).

18 Sofroniew, M. V. Molecular dissection of reactive astrogliosis and glial scar formation. Trends Neurosci 32, 638-647, (2009).

19 Liddelow, S. A. et al. Neurotoxic reactive astrocytes are induced by activated microglia. Nature 541, 481-487, (2017).

20 Escartin, C. et al. Reactive astrocyte nomenclature, definitions, and future directions. Nat Neurosci 24, 312-325, (2021).

21 Faulkner, J. R. et al. Reactive astrocytes protect tissue and preserve function after spinal cord injury. $J$ Neurosci 24, 2143-2155, (2004).

22 Bellver-Landete, V. et al. Microglia are an essential component of the neuroprotective scar that forms after spinal cord injury. Nat Commun 10, 518, (2019). 
23 Almad, A., Sahinkaya, F. R. \& McTigue, D. M. Oligodendrocyte fate after spinal cord injury. Neurotherapeutics 8, 262-273, (2011).

24 Plemel, J. R. et al. Remyelination after spinal cord injury: is it a target for repair? Prog Neurobio/ 117, 54-72, (2014).

25 Lytle, J. M. \& Wrathall, J. R. Glial cell loss, proliferation and replacement in the contused murine spinal cord. Eur J Neurosci 25, 1711-1724, (2007).

26 Liu, X. Z. et al. Neuronal and glial apoptosis after traumatic spinal cord injury. J Neurosci 17, 53955406, (1997).

27 Crowe, M. J., Bresnahan, J. C., Shuman, S. L., Masters, J. N. \& Beattie, M. S. Apoptosis and delayed degeneration after spinal cord injury in rats and monkeys. Nat Med 3, 73-76., (1997).

28 Emery, E. et al. Apoptosis after traumatic human spinal cord injury. J Neurosurg 89, 911-920, (1998).

29 Li, G. L., Farooque, M., Holtz, A. \& Olsson, Y. Apoptosis of oligodendrocytes occurs for long distances away from the primary injury after compression trauma to rat spinal cord. Acta Neuropatho/ $98,473-480$, (1999).

30 Casha, S., Yu, W. R. \& Fehlings, M. G. Oligodendroglial apoptosis occurs along degenerating axons and is associated with FAS and p75 expression following spinal cord injury in the rat. Neuroscience 103, 203-218, (2001).

31 Blight, A. R. Delayed demyelination and macrophage invasion: a candidate for secondary cell damage in spinal cord injury. Cent Nerv Syst Trauma 2, 299-315., (1985).

32 Blight, A. R. Axonal physiology of chronic spinal cord injury in the cat: intracellular recording in vitro. Neuroscience 10, 1471-1486, (1983).

33 Siegenthaler, M. M., Tu, M. K. \& Keirstead, H. S. The extent of myelin pathology differs following contusion and transection spinal cord injury. J Neurotrauma 24, 1631-1646, (2007).

34 James, N. D. et al. Conduction failure following spinal cord injury: functional and anatomical changes from acute to chronic stages. J Neurosci 31, 18543-18555, (2011).

35 Pineau, I. \& Lacroix, S. Endogenous signals initiating inflammation in the injured nervous system. Glia 57, 351-361, (2009).

36 Gadani, S. P., Walsh, J. T., Lukens, J. R. \& Kipnis, J. Dealing with Danger in the CNS: The Response of the Immune System to Injury. Neuron 87, 47-62, (2015).

37 Mailhot, B. et al. Neuronal interleukin-1 receptors mediate pain in chronic inflammatory diseases. $J$ Exp Med 217, (2020). 
38 Rider, P. et al. IL-1 \{alpha\} and IL-1 \{beta\} Recruit Different Myeloid Cells and Promote Different Stages of Sterile Inflammation. J Immuno/ 187, 4835-4843, (2011).

39 Floriddia, E. M. et al. Distinct oligodendrocyte populations have spatial preference and different responses to spinal cord injury. Nat Commun 11, 5860, (2020).

40 Abbate, A. et al. Interleukin-1 and the Inflammasome as Therapeutic Targets in Cardiovascular Disease. Circ Res 126, 1260-1280, (2020).

41 Qian, J. et al. Interleukin-1R3 mediates interleukin-1-induced potassium current increase through fast activation of Akt kinase. Proc Natl Acad Sci U S A 109, 12189-12194, (2012).

42 Liu, X. et al. Interleukin 1 type 1 receptor restore: a genetic mouse model for studying interleukin 1 receptor-mediated effects in specific cell types. J Neurosci 35, 2860-2870, (2015).

43 Hauptmann, J. et al. Interleukin-1 promotes autoimmune neuroinflammation by suppressing endothelial heme oxygenase-1 at the blood-brain barrier. Acta Neuropathol 140, 549-567, (2020).

44 Joshi, A. U. et al. Fragmented mitochondria released from microglia trigger A1 astrocytic response and propagate inflammatory neurodegeneration. Nat Neurosci 22, 1635-1648, (2019).

45 Juurlink, B. H. Response of glial cells to ischemia: roles of reactive oxygen species and glutathione. Neurosci Biobehav Rev 21, 151-166, (1997).

46 Nikic, I. et al. A reversible form of axon damage in experimental autoimmune encephalomyelitis and multiple sclerosis. Nat Med 17, 495-499, (2011).

47 Cavalli, G. et al. Interleukin 1alpha: a comprehensive review on the role of IL-1alpha in the pathogenesis and treatment of autoimmune and inflammatory diseases. Autoimmun Rev, 102763, (2021).

48 Buryskova, M., Pospisek, M., Grothey, A., Simmet, T. \& Burysek, L. Intracellular interleukin-1alpha functionally interacts with histone acetyltransferase complexes. J Biol Chem 279, 4017-4026, (2004).

49 Werman, A. et al. The precursor form of IL-1alpha is an intracrine proinflammatory activator of transcription. Proc Natl Acad Sci U S A 101, 2434-2439, (2004).

$50 \mathrm{Kim}, \mathrm{B}$. et al. The interleukin-1 alpha precursor is biologically active and is ikely a key alarmin in the IL-1 family of cytokines. Front Immuno/ 4, 391, (2013).

51 Afonina, I. S. et al. Granzyme B-dependent proteolysis acts as a switch to enhance the proinflammatory activity of IL-1alpha. Mol Cel/ 44, 265-278, (2011).

52 Chen, C. J. et al. Identification of a key pathway required for the sterile inflammatory response triggered by dying cells. Nat Med 13, 851-856, (2007). 
53 Cohen, I. et al. Differential release of chromatin-bound IL-1alpha discriminates between necrotic and apoptotic cell death by the ability to induce sterile inflammation. Proc Natl Acad Sci U S A 107, 25742579, (2010).

54 Vela, J. M., Molina-Holgado, E., Arevalo-Martin, A., Almazan, G. \& Guaza, C. Interleukin-1 regulates proliferation and differentiation of oligodendrocyte progenitor cells. Mol Cell Neurosci 20, 489-502, (2002).

55 Serrats, J. et al. Dual roles for perivascular macrophages in immune-to-brain signaling. Neuron 65 , 94-106, (2010).

56 Basu, A. et al. The type 1 interleukin-1 receptor is essential for the efficient activation of microglia and the induction of multiple proinflammatory mediators in response to brain injury. J Neurosci 22, 60716082, (2002).

57 Bruttger, J. et al. Genetic Cell Ablation Reveals Clusters of Local Self-Renewing Microglia in the Mammalian Central Nervous System. Immunity 43, 92-106, (2015).

58 Pinteaux, E., Parker, L. C., Rothwell, N. J. \& Luheshi, G. N. Expression of interleukin-1 receptors and their role in interleukin-1 actions in murine microglial cells. J Neurochem 83, 754-763, (2002).

59 Pineau, I., Libo, S., Bastien, D. \& Lacroix, S. Astrocytes initiate inflammation in the injured mouse spinal cord by promoting the entry of neutrophils and inflammatory monocytes in an IL-1 receptor/MyD88-dependent fashion. Brain Behav Immun 24, 540-553, (2010).

60 Oluich, L. J. et al. Targeted ablation of oligodendrocytes induces axonal pathology independent of overt demyelination. J Neurosci 32, 8317-8330, (2012).

61 Traka, M. et al. A genetic mouse model of adult-onset, pervasive central nervous system demyelination with robust remyelination. Brain 133, 3017-3029, (2010).

62 Pohl, H. B. et al. Genetically induced adult oligodendrocyte cell death is associated with poor myelin clearance, reduced remyelination, and axonal damage. J Neurosci 31, 1069-1080, (2011).

63 Snaidero, N. et al. Myelin replacement triggered by single-cell demyelination in mouse cortex. Nat Commun 11, 4901, (2020).

64 Hesp, Z. C., Goldstein, E. Z., Miranda, C. J., Kaspar, B. K. \& McTigue, D. M. Chronic oligodendrogenesis and remyelination after spinal cord injury in mice and rats. J Neurosci 35, 1274-1290, (2015).

65 Duncan, G. J. et al. Locomotor recovery following contusive spinal cord injury does not require oligodendrocyte remyelination. Nat Commun 9, 3066, (2018). 
$66 \mathrm{Liu}, \mathrm{X}$. et al. Cell-type-specific interleukin 1 receptor 1 signaling in the brain regulates distinct neuroimmune activities. Immunity 50, 764-766, (2019).

67 Freria, C. M. et al. Serial Systemic Injections of Endotoxin (LPS) Elicit Neuroprotective Spinal Cord Microglia through IL-1-Dependent Cross Talk with Endothelial Cells. J Neurosci 40, 9103-9120, (2020).

68 Okada, S. et al. Conditional ablation of Stat3 or Socs3 discloses a dual role for reactive astrocytes after spinal cord injury. Nat Med 12, 829-834, (2006).

69 Brambilla, R. et al. Inhibition of astroglial nuclear factor kappaB reduces inflammation and improves functional recovery after spinal cord injury. J Exp Med 202, 145-156, (2005).

70 Brambilla, R. et al. Transgenic inhibition of astroglial NF-kappaB leads to increased axonal sparing and sprouting following spinal cord injury. J Neurochem 110, 765-778, (2009).

71 Bradbury, E. J. et al. Chondroitinase ABC promotes functional recovery after spinal cord injury. Nature 416, 636-640., (2002).

72 McKeon, R. J., Schreiber, R. C., Rudge, J. S. \& Silver, J. Reduction of neurite outgrowth in a model of glial scarring following CNS injury is correlated with the expression of inhibitory molecules on reactive astrocytes. J Neurosci 11, 3398-3411., (1991).

73 Anderson, M. A. et al. Astrocyte scar formation aids central nervous system axon regeneration. Nature 532, 195-200, (2016).

74 Giacci, M. K. et al. Oligodendroglia Are Particularly Vulnerable to Oxidative Damage after Neurotrauma In Vivo. J Neurosci 38, 6491-6504, (2018).

75 Patel, S. P. et al. N-acetylcysteine amide preserves mitochondrial bioenergetics and improves functional recovery following spinal trauma. Exp Neurol 257, 95-105, (2014).

76 Eakin, K. et al. Efficacy of N-acetyl cysteine in traumatic brain injury. PLoS One 9, e90617, (2014).

77 Guo, J. et al. N-acetylcysteine treatment following spinal cord trauma reduces neural tissue damage and improves locomotor function in mice. Mol Med Rep 12, 37-44, (2015).

78 Anderson, A. J., Robert, S., Huang, W., Young, W. \& Cotman, C. W. Activation of complement pathways after contusion-induced spinal cord injury. J Neurotrauma 21, 1831-1846, (2004).

79 Pineau, I. \& Lacroix, S. Proinflammatory cytokine synthesis in the injured mouse spinal cord:

Multiphasic expression pattern and identification of the cell types involved. $J$ Comp Neuro/ 500, 267-285, (2007).

80 Harlan, J. M. Consequences of leukocyte-vessel wall interactions in inflammatory and immune reactions. Semin Thromb Hemost 13, 434-444., (1987). 
81 Nguyen, H. X., O'Barr, T. J. \& Anderson, A. J. Polymorphonuclear leukocytes promote neurotoxicity through release of matrix metalloproteinases, reactive oxygen species, and TNF-alpha. J Neurochem 102, 900-912, (2007).

82 Allen, C. et al. Neutrophil cerebrovascular transmigration triggers rapid neurotoxicity through release of proteases associated with decondensed DNA. J Immunol 189, 381-392, (2012).

83 David, S. \& Kroner, A. Repertoire of microglial and macrophage responses after spinal cord injury. Nat Rev Neurosci 12, 388-399, (2011).

84 Kigerl, K. A. et al. Identification of two distinct macrophage subsets with divergent effects causing either neurotoxicity or regeneration in the injured mouse spinal cord. J Neurosci 29, 13435-13444, (2009).

85 Faget, J. et al. Efficient and specific Ly6G+ cell depletion: A change in the current practices toward more relevant functional analyses of neutrophils. BioRxiv 498881, (2018).

86 Yona, S. et al. Fate mapping reveals origins and dynamics of monocytes and tissue macrophages under homeostasis. Immunity 38, 79-91, (2013).

87 Madisen, L. et al. A robust and high-throughput Cre reporting and characterization system for the whole mouse brain. Nat Neurosci 13, 133-140, (2010).

88 Kang, S. H., Fukaya, M., Yang, J. K., Rothstein, J. D. \& Bergles, D. E. NG2+ CNS glial progenitors remain committed to the oligodendrocyte lineage in postnatal life and following neurodegeneration. Neuron 68 , 668-681, (2010).

89 Gregorian, C. et al. Pten deletion in adult neural stem/progenitor cells enhances constitutive neurogenesis. J Neurosci 29, 1874-1886, (2009).

90 Robson, M. J. et al. Generation and Characterization of Mice Expressing a Conditional Allele of the Interleukin-1 Receptor Type 1. PLoS One 11, e0150068, (2016).

91 Sorensen, I., Adams, R. H. \& Gossler, A. DLL1-mediated Notch activation regulates endothelial identity in mouse fetal arteries. Blood 113, 5680-5688, (2009).

92 Basso, D. M. et al. Basso Mouse Scale for locomotion detects differences in recovery after spinal cord injury in five common mouse strains. J Neurotrauma 23, 635-659, (2006).

93 Emery, B. \& Dugas, J. C. Purification of oligodendrocyte lineage cells from mouse cortices by immunopanning. Cold Spring Harb Protoc 2013, 854-868, (2013).

94 Schildge, S., Bohrer, C., Beck, K. \& Schachtrup, C. Isolation and culture of mouse cortical astrocytes. Journal of visualized experiments : JoVE 71, 50079, (2013). 
95 Haines, J. D. et al. Nuclear export inhibitors avert progression in preclinical models of inflammatory demyelination. Nat Neurosci 18, 511-520, (2015).

\section{Figures}
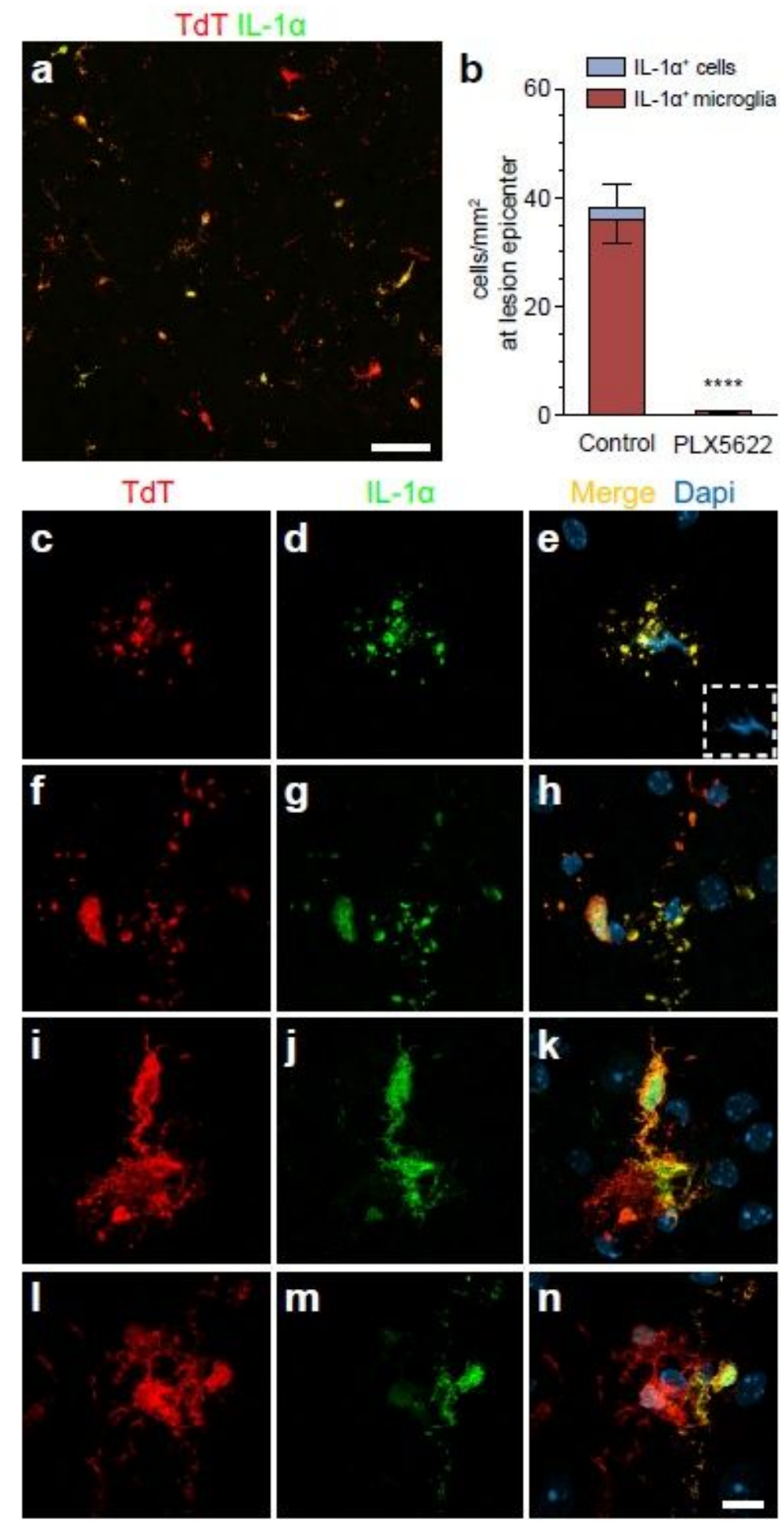

Figure 1 
Damaged microglia rapidly release IL-1a at the site of spinal cord contusion in mice. (A) Representative confocal image showing IL-1a immunostaining (green) in the spinal cord of an injured Cx3cr1Cre::Rosa26TdT transgenic mouse, in which microglia express the fluorescent reporter Td-Tomato (TdT, red), at 4 hours post-SCI. (B) Quantification of IL-1a-positive (+) cells at the lesion epicenter in CX3cr1Cre::Rosa26TdT mice treated with PLX5622 or the control diet and killed at 4 hours post-SCI $(n=3$ mice/group). (C-N) High magnification confocal images of IL-1a+ TdT+ microglia revealed that these cells often exhibit damaged cell bodies and processes $(\mathrm{C}-\mathrm{H})$ or have retracted, swollen processes, indicative of an activated status (I-N). Nuclear staining (DAPI) is shown in blue $(E, H, K, N)$ in the merged images. Data are expressed as mean \pm SEM. $* \star \star ~ p<0.001$, PLX5622 compared to the control diet group; one-way ANOVA with Bonferroni's post-hoc test. Scale bars: (A) $50 \mu \mathrm{m}$, (C-N, in N) $50 \mu \mathrm{m}$.
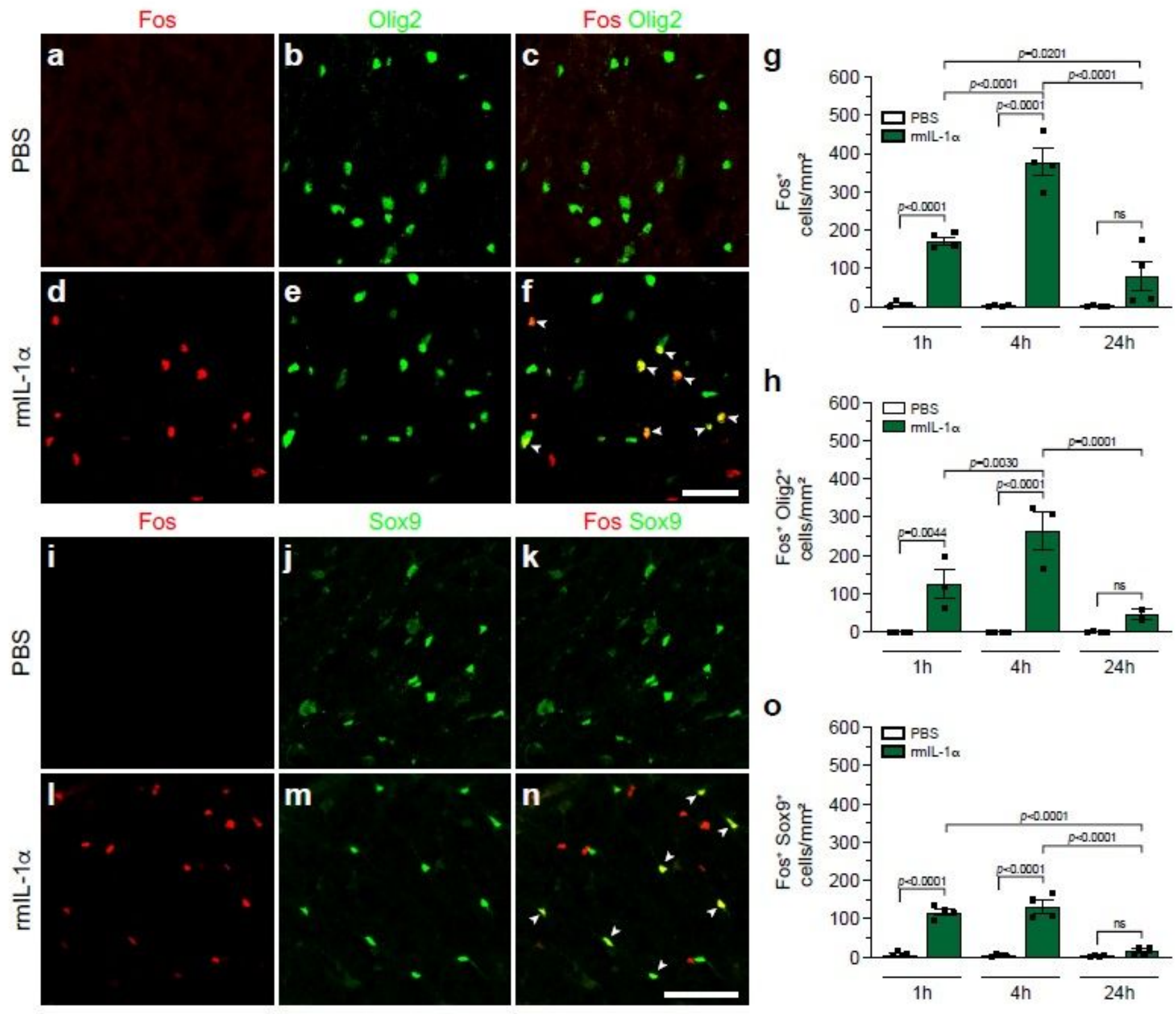

h
के
한.

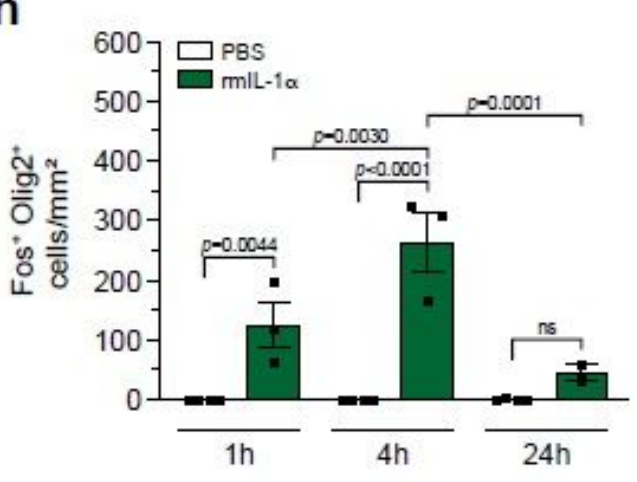

o

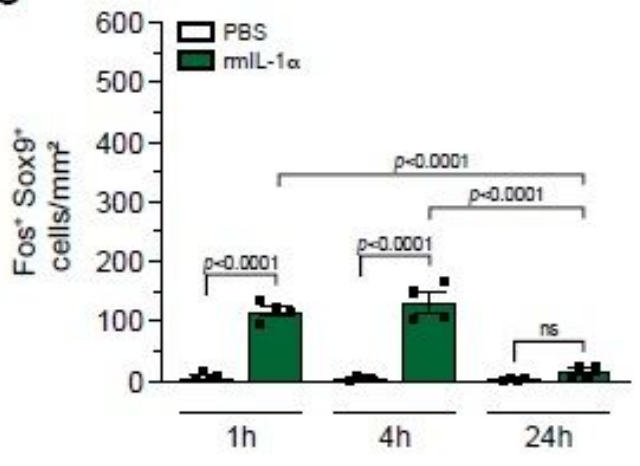

Figure 2 
Intra-cisterna magna injection of IL-1a in mice induces rapid activation of astrocytes and oligodendrocytes throughout the spinal cord. (A-F, I-N) Representative confocal images of the spinal cord showing expression of the cell activation marker Fos (red signal) in Olig2+ oligodendrocyte (OL) lineage cells (green cells in A-F) and Sox9+ astrocytes (green cells in I-N) at 4 hours after a single intra-cisterna magna (i.c.m.) injection of either PBS (A-C, I-K) or recombinant mouse (rm) IL-1 a (D-F, L-N). White arrowheads point to some double-labeled cells. (G-H) Quantification of the total number of Fos+ cells (G) and Fos+Olig2+ double-labeled OLs $(\mathrm{H})$ in the spinal cord white matter of C57BL/6 mice injected with either PBS or rmIL-1 $a$ and killed at 1, 4 or 24 hours post-injection ( $n=3-4$ mice/group). (0) Quantification of the total number of Fos+Sox9+ double-labeled astrocytes in the spinal cord white matter $(n=3-4$ mice/group). Data are expressed as mean \pm SEM. Statistical significance was determined by a two-way ANOVA followed by a Bonferroni post-hoc test. Pairwise comparisons and $p$-values are indicated in the graphs. Scale bars: (A-F, in F) $50 \mu \mathrm{m},(I-N$, in N) $50 \mu \mathrm{m},(P-U$, in $U) 50 \mu \mathrm{m}$.
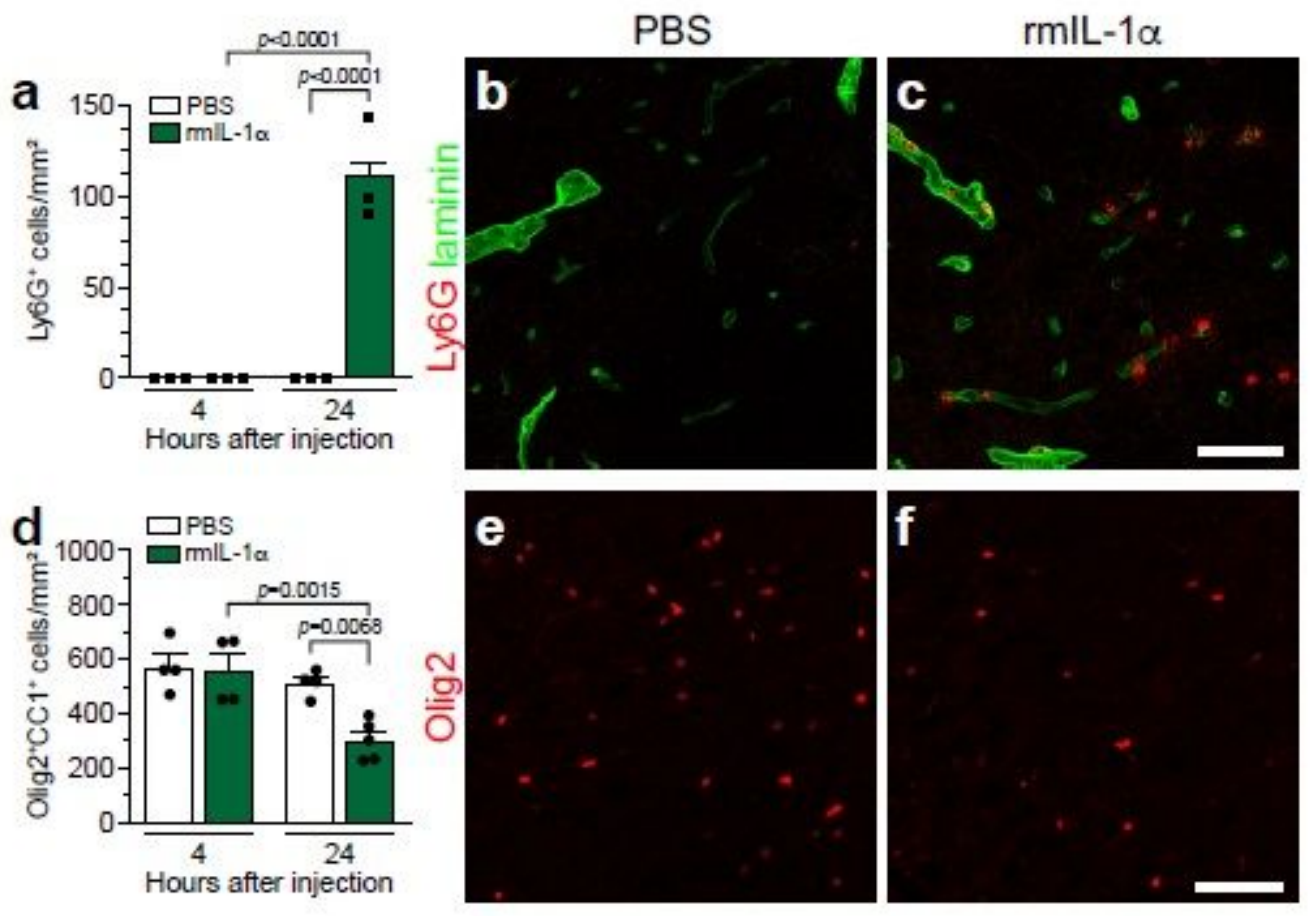

\section{Figure 3}

Intra-cisterna magna injection of IL-1a in mice induces innate immune cell infiltration and loss of mature oligodendrocytes throughout the spinal cord. (A) Quantification of the total number of Ly6G+ neutrophils that infiltrated the spinal cord at 4 and 24 hours post-injection of PBS or recombinant mouse (rm) IL-1a intra-cisterna magna (i.c.m.) (n=5 mice/group). (B-C) Representative confocal images showing Ly6G (a marker of neutrophils, red) and laminin (a marker of blood vessel basement membranes, green) immunostainings in the spinal cord of C57BL/6 mice injected with either PBS (B) or rmIL-1a (C) at 24 hours post-injection. (D) Quantification of the total number of Olig2+CC1+ mature oligodendrocytes in the spinal cord white matter of C57BL/ 6 mice at 4 and 24 hours post-i.c.m. injection of either PBS or rmlL-1a 
( $n=4-5$ mice/group/time). (E-F) Representative confocal images showing immunostaining for the oligodendrocyte transcription factor 2 (Olig2, red cells), a nuclear marker of oligodendrocyte lineage cells, in the spinal cord of C57BL/ 6 mice at 24 hours post-injection of either PBS (E) or rmIL-1a (F). Statistical significance was determined by a two-way ANOVA followed by a Bonferroni post-hoc test. Pairwise comparisons and p-values are indicated in the graphs. Scale bars: (B-C, in C) $50 \mu \mathrm{m}$, (E-F, in F) $50 \mu \mathrm{m}$.
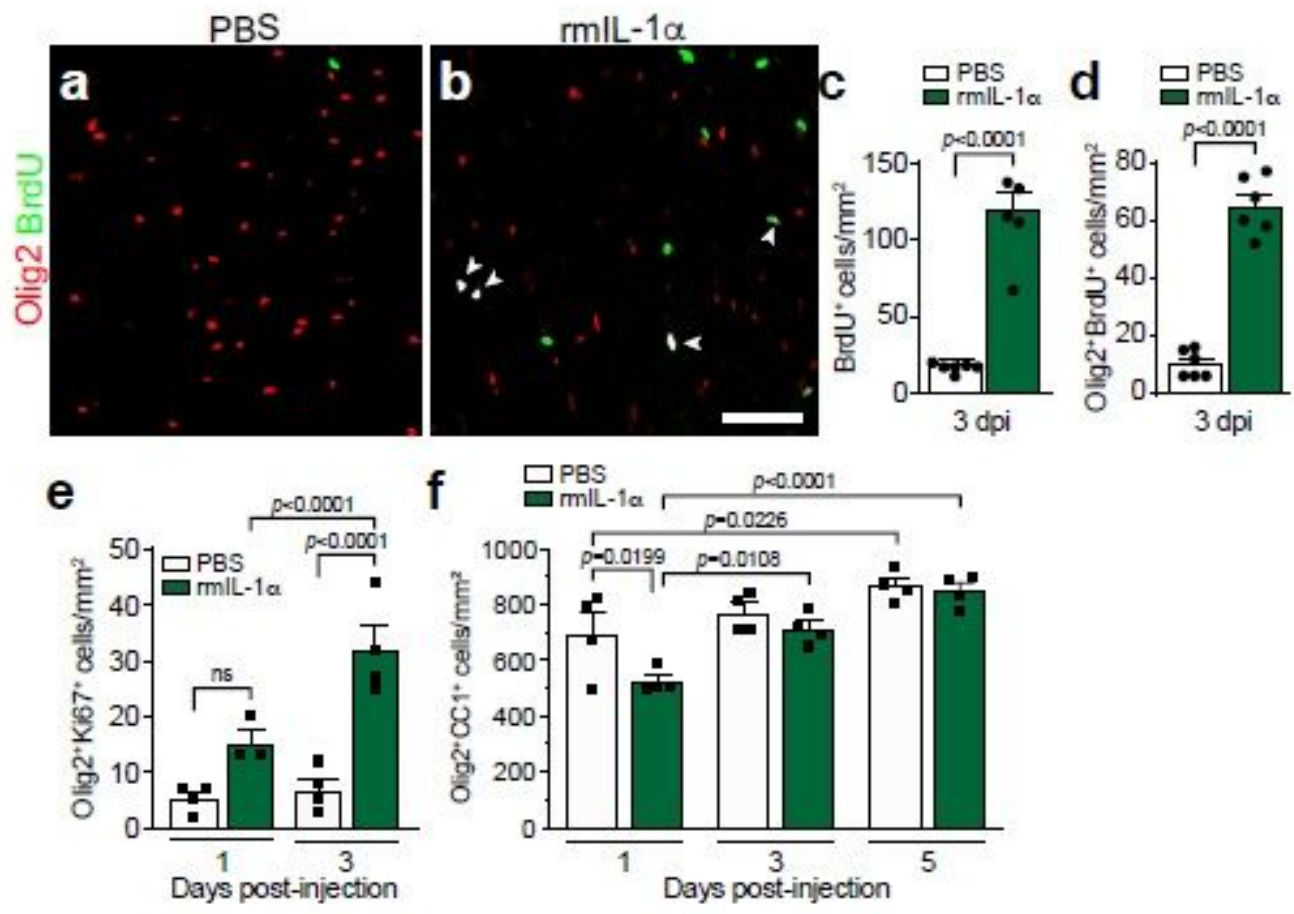

\section{Figure 4}

Proliferating Olig2+ cells rapidly restore the number of mature oligodendrocytes in mice injected centrally with IL-1a. (A-B) Representative confocal images showing Olig2 (red) and BrdU (a marker of cell proliferation, green) immunostainings in the spinal cord white matter of C57BL/ 6 mice injected with either PBS (A) or recombinant mouse ( $\mathrm{rm}) \mathrm{IL}-1 \mathrm{a}(\mathrm{B})$ at 3 days post-injection. White arrowheads point to some proliferating oligodendrocyte lineage cells. (C-D) Quantification of the total number of BrdU+ cells (C) and Olig2+BrdU+ double-positive cells (D) in the spinal cord white matter at 3 days post-injection of PBS or rmlL-1 a intra-cisterna magna (i.c.m.) ( $n=6$ mice/group). (E) Quantification of the total number of Olig2+Ki67+ double-positive cells in the spinal cord white matter of C57BL/ 6 mice at 1 and 3 days posti.c.m. injection of either PBS or rmlL-1a ( $n=3-4$ mice/group/time). (F) Quantification of the total number of Olig2+ $\mathrm{CC} 1+$ mature oligodendrocytes in the spinal cord white matter at 1, 3 and 5 days post-i.c.m. treatment ( $\mathrm{n}=4$ mice/group). Statistical significance was determined by either a one (C-D) or two-way (EF) ANOVA followed by a Bonferroni post-hoc test. Pairwise comparisons and p-values are indicated in the graphs. Scale bars: (A-B, in B) $50 \mu \mathrm{m}$. 


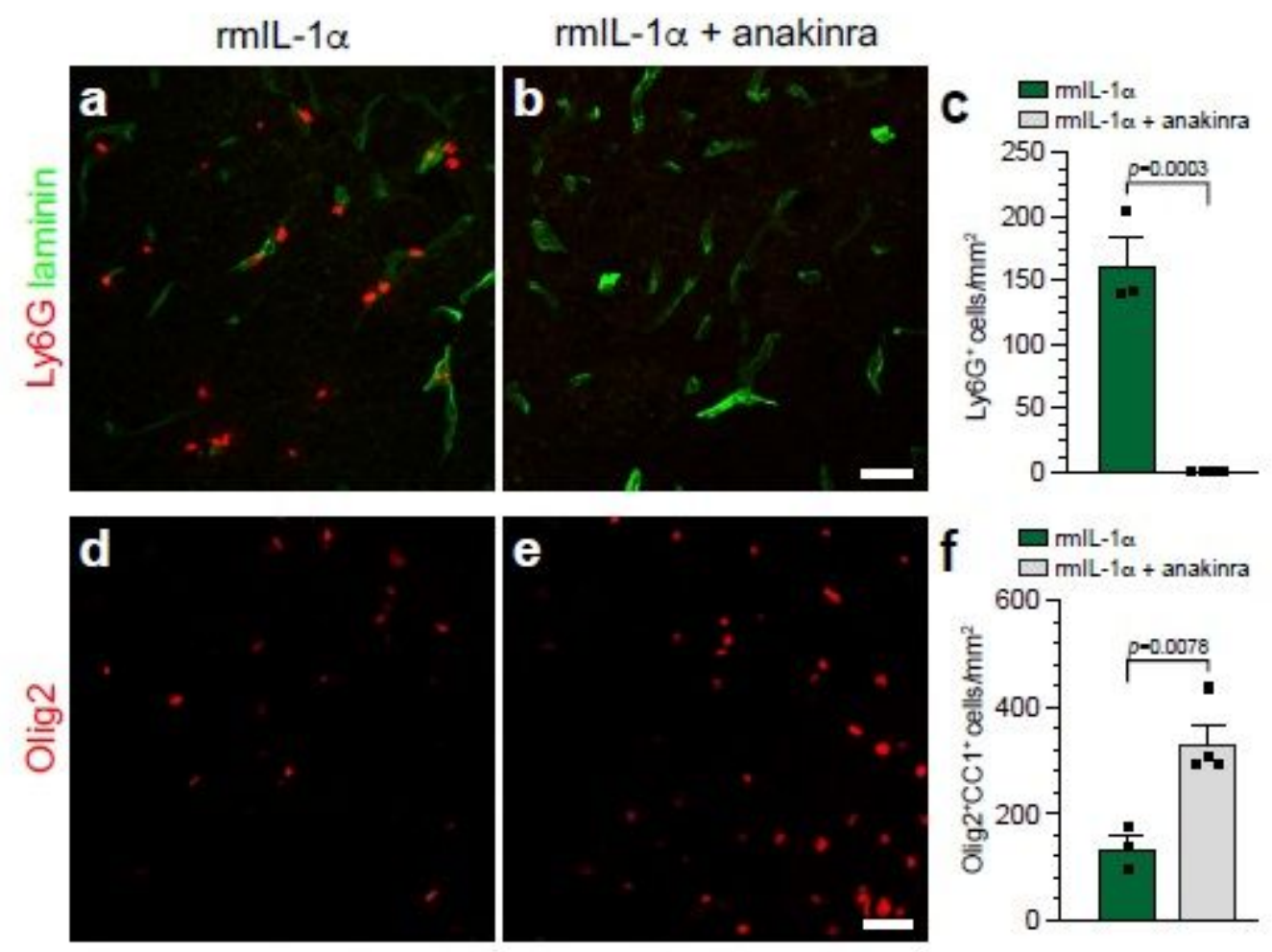

\section{Figure 5}

Delivery of the IL-1 receptor antagonist anakinra in the cerebrospinal fluid blocks the effects of IL-1a on neutrophil infiltration and oligodendrocyte loss. (A-B) Representative confocal images showing the presence (or absence) of Ly6G+ neutrophils (red cells) in the spinal cord of C57BL/ 6 mice injected intracisterna magna (i.c.m.) with either recombinant mouse (rm) IL-1a alone (A) or rmIL-1a + anakinra (B), a recombinant human IL-1R antagonist. All mice were killed at 24 hours post-injection. An anti-pan-laminin antibody was used to stain blood vessel basement membranes (green staining). (C) Quantification of the total number of Ly6G+ neutrophils that infiltrated the spinal cord of mice ( $n=3-4$ mice/group). (D-E) Representative images showing immunostaining for the Olig2 transcription factor, a marker of cells of the oligodendrocyte lineage, in the spinal cord of C57BL/ 6 mice injected with either rmIL-1a (D) or rmIL-1a + anakinra (E). All mice were killed at 24 hours post-injection ( $n=3-4$ mice/group). ( $F$ ) Quantification of the total number of Olig2+ $\mathrm{CC} 1+$ mature oligodendrocytes in the spinal cord white matter at 24 hours posti.c.m. treatment ( $n=3-4$ mice/group). Statistical comparisons were made using a Student's t-test and $p$ values are indicated in the graphs. Scale bars: (A-B, in B) $25 \mu \mathrm{m}$, (D-E, in E) $25 \mu \mathrm{m}$. 
a

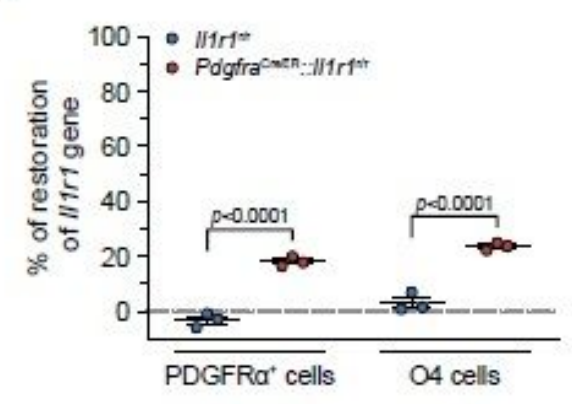

b

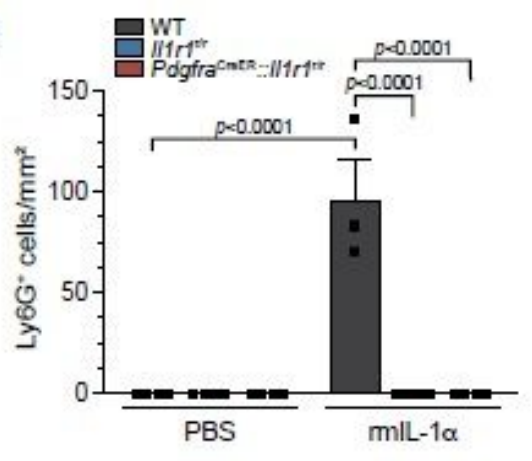

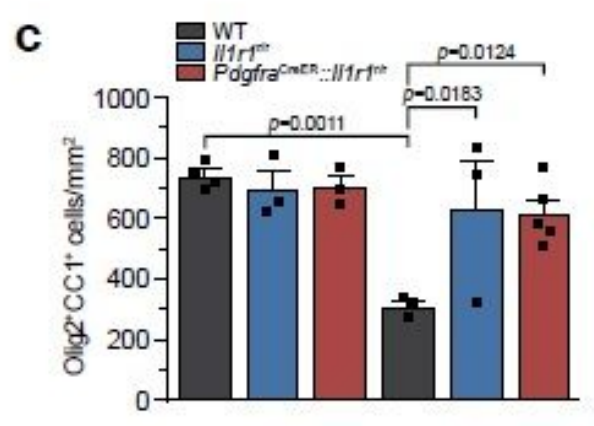

\section{Figure 6}

Restoration of the II1 r1 gene in oligodendrocyte lineage cells does not allow for IL-1a-mediated neuroinflammation and oligodendrocyte loss. (A) Quantification of restoration of $\| 1 \mathrm{r} 1$ gene expression in primary PDGFR+ and 04+ oligodendrocyte lineage cells isolated by immunopanning from the uninjured spinal cord of adult II1 r1 r/r mice, which express an IL-1R1-knockout phenotype, and PdgfraCreER::I1 $1 \mathrm{r} 1 \mathrm{r} / \mathrm{r}$ mice at 50 days post-tamoxifen treatment. (B) Quantification of the number of Ly6G+ neutrophils that infiltrated the spinal cord of WT, II1 r1 r/r and PdgfraCreER::Il1r1r/r mice at 24 hours post-injection of either PBS or rmlL-1a ( $n=3-4$ mice/group). (C) Quantification of the total number of Olig2+ CC1+ mature oligodendrocytes in the spinal cord white matter of WT, $\| 1 \mathrm{r} 1 \mathrm{r} / \mathrm{r}$ and PdgfraCreER::Il1r1r/r mice at 24 hours post-injection of either PBS or rmIL-1a ( $n=3-5$ mice/group). Statistical significance was determined by either a Student's t-test (A) or a two-way ANOVA followed by a Bonferroni post-hoc test (B-C). Pairwise comparisons and $p$-values are indicated in the graphs. 

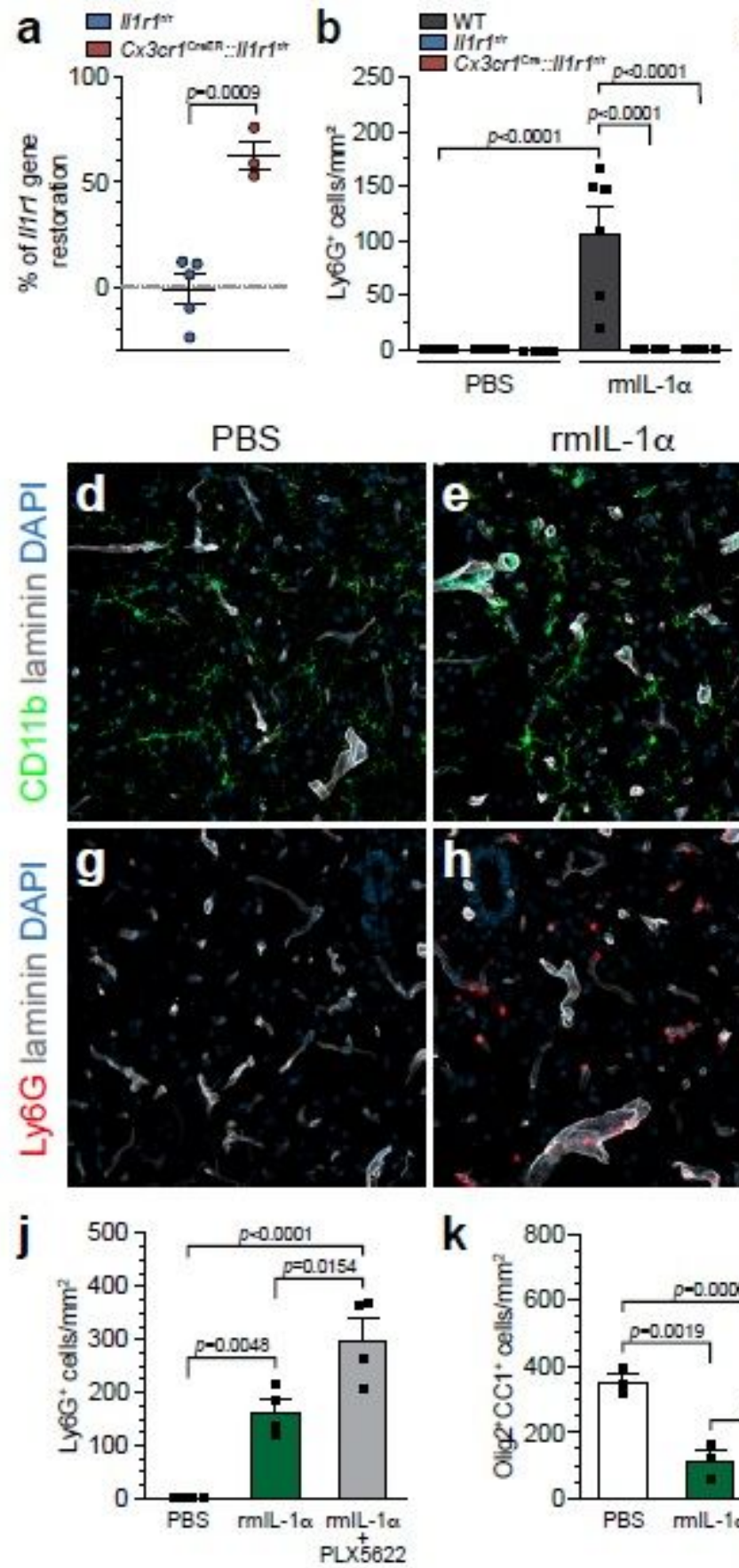

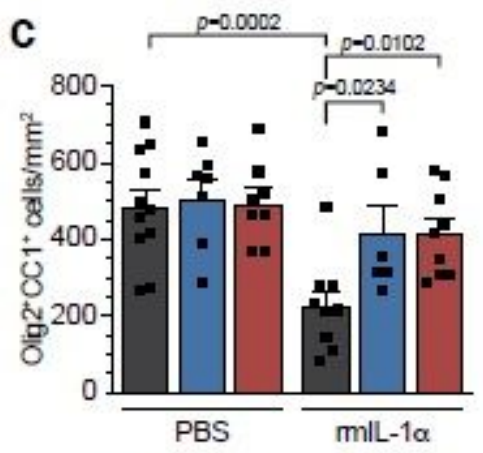

rmIL-1 $\alpha+$ PLX5622
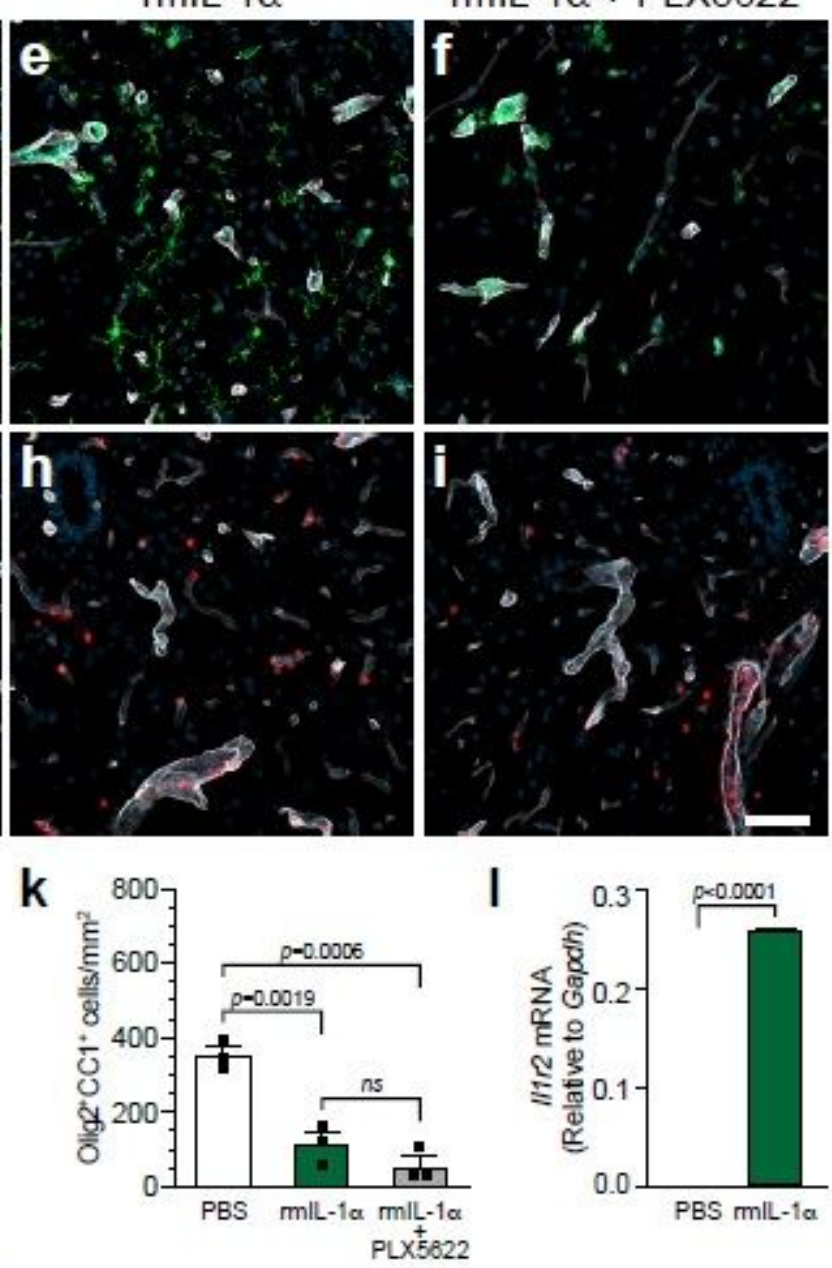

\section{Figure 7}

Microglia alleviate IL-1a-mediated neuroinflammation and oligodendrocyte loss independently of their expression of IL-1R1. (A) Quantification of restoration of II1 $\mathrm{r} 1$ gene expression in primary microglia isolated from the uninjured spinal cord of adult II $1 \mathrm{r} 1 \mathrm{r} / \mathrm{r}$ mice, which express an IL-1R1-knockout phenotype (set to $0 \%$ ), and $\mathrm{Cx} 3 \mathrm{cr} 1 \mathrm{CreER}: . \| 1 \mathrm{r} 1 \mathrm{r} / \mathrm{r}$ mice at 30 days post-tamoxifen treatment $(\mathrm{n}=3-5$ mice/group). (B) Quantification of the number of Ly6G+ neutrophils that infiltrated the spinal cord of WT, $\| 1 \mathrm{r} 1 \mathrm{r} / \mathrm{r}$ and $\mathrm{Cx} 3 \mathrm{cr} 1 \mathrm{CreER}:: \| 1 \mathrm{r} 1 \mathrm{r} / \mathrm{r}$ mice at 24 hours post-injection of either PBS or rmlL-1a $(\mathrm{n}=6-11$ mice/group). (C) Quantification of the total number of Olig2+ CC1+ mature oligodendrocytes (OLs) in the 
spinal cord white matter of WT, $I 1 \mathrm{r} 1 \mathrm{r} / \mathrm{r}$ and Cx3cr1CreER::Il1 $1 \mathrm{r} r / \mathrm{r}$ mice at 24 hours post-injection of either PBS or rmIL-1a ( $n=6-11$ mice/group). (D-I) Representative confocal images showing the presence of CD11b+ cells (green cells in D-F; CD11b stains microglia, macrophages and neutrophils) and Ly6G+ neutrophils (red cells in G-I) in the spinal cord of C57BL/6 mice injected with either PBS (D, G), rmIL-1a (E, H) or rmIL-1a + PLX5622 (a CSF1R inhibitor from Plexxikon; F, I) at 24 hours post-injection. (J) Quantification of the total number of Ly6G+ neutrophils that infiltrated the spinal cord of C57BL/6 mice at 24 hours post-injection of either PBS or rmIL-1a ( $n=4$ mice/group). (K) Quantification of the total number of Olig2 $+\mathrm{CC} 1+$ mature OLs in the spinal cord white matter of C57BL/ 6 mice at 24 hours postinjection of either PBS or rmlL-1a ( $n=3-4$ mice/group). For all experiments involving PLX5622 (F, I-K), mice were fed the PLX5622 diet for 3 weeks before the experimentation to deplete all microglia. ( $L$ ) Relative expression of II1r2 gene, as determined by quantitative real-time PCR. Gapdh expression levels were used to normalize data. Statistical significance was determined by either a Student's t-test (A, L), one-way ANOVA (J-K), or two-way ANOVA (B-C) followed by a Bonferroni post-hoc test. Pairwise comparisons and p-values are indicated in the graphs. Scale bars: (D-I, in I) $50 \mu \mathrm{m}$. 
a

Restoration of $\| 11 \mathrm{r}^{\mathrm{nr}}$ allele

LoxP LoxP TAG

-4 STOP 4

with cre
recombinase

Restored II1r1 allele

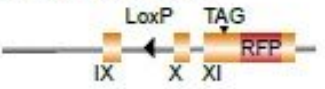

e

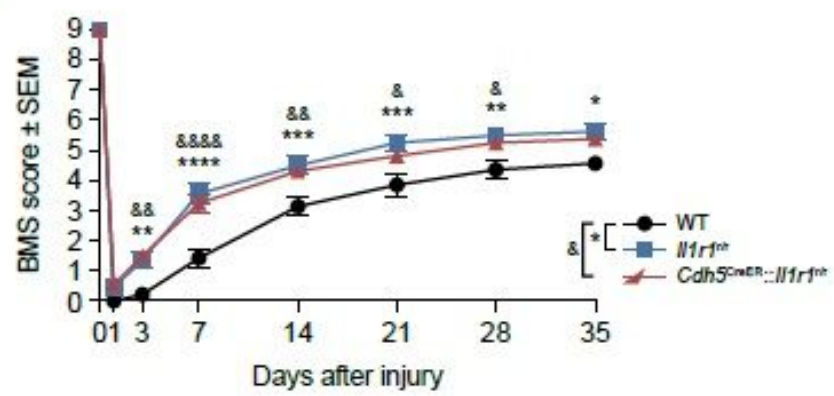

c

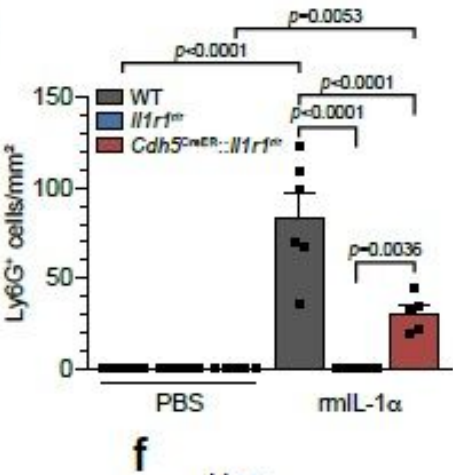

f
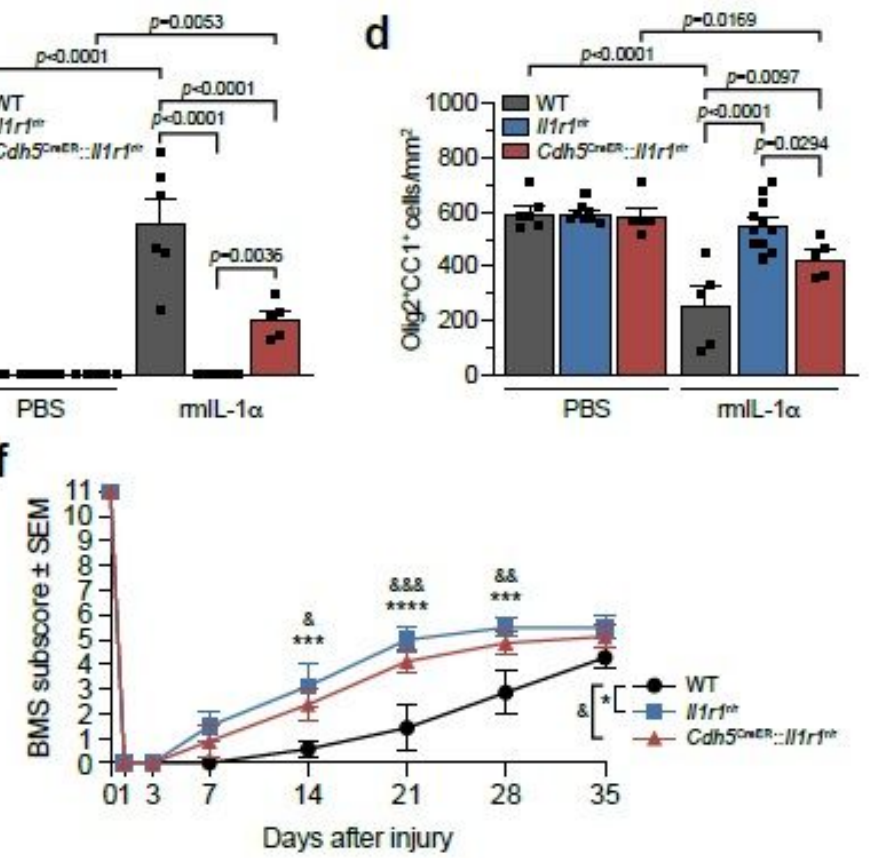

g

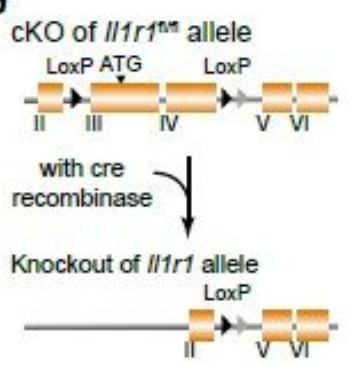

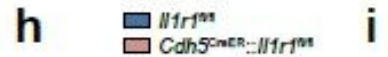

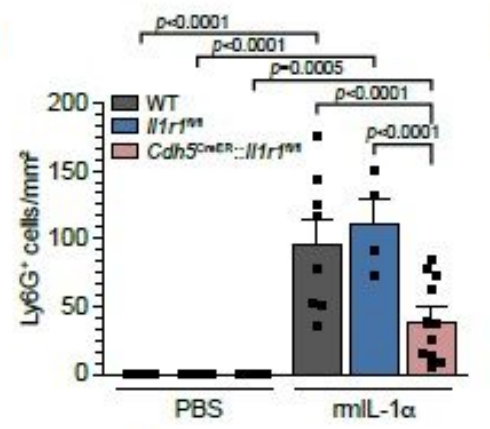

j

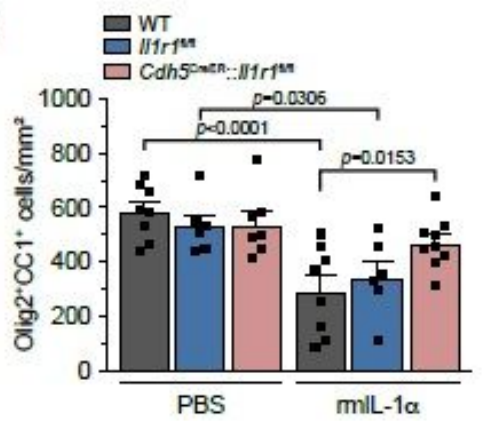

k

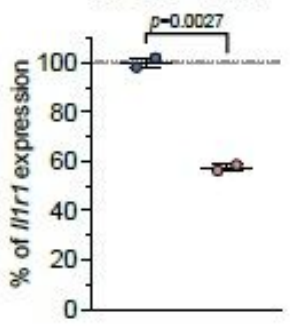

I
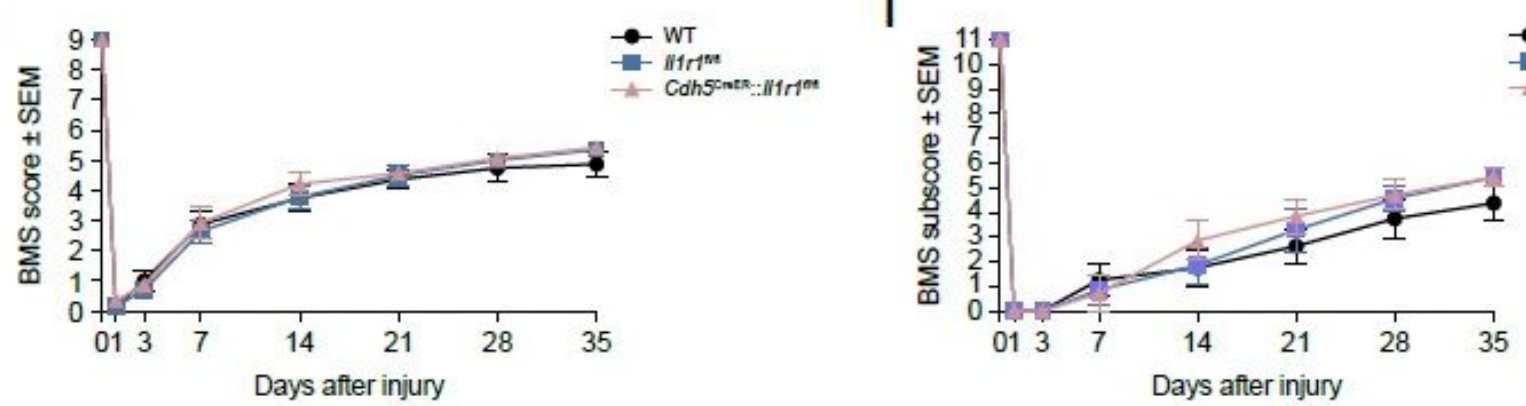

\section{Figure 8}

IL-1a-induced neuroinflammation and oligodendrocyte loss is partly mediated by endothelial IL-1R1. (A) Schematic diagram showing the genetic design of the Cdh5CreER::Il1r1r/r mouse line. (B) Quantification of restoration of $\| 1 \mathrm{r} 1$ gene expression in primary endothelial cells isolated from the brain of naïve adult IIr1r/r mice, which express an IL-1R1-knockout phenotype (set to 0\%), and Cdh5CreER::Il1r1r/r mice at 30 days post-tamoxifen treatment. (C) Quantification of the total number of Ly6G+ neutrophils that infiltrated the spinal cord of WT, $\| 1 \mathrm{r} 1 \mathrm{r} / \mathrm{r}$ and Cdh5CreER::Il1r1r/r mice at 24 hours post-injection of either PBS or recombinant mouse (rm) IL-1 a intra-cisterna magna ( $n=5-6$ mice/group). (D) Quantification of the total number of Olig2+ CC1+ mature OLs in the spinal cord white matter of WT, II r r r $/ \mathrm{r}$ and 
Cdh5CreER::II1 r1r/r mice at 24 hours post-injection of either PBS or rmIL-1a ( $n=5-11$ mice/group). (E-F) Locomotor function was assessed using the BMS score (E) and BMS subscore (F) over a 35-day period after $\mathrm{SCl}$ in $\mathrm{WT}, \| 1 \mathrm{r} 1 \mathrm{r} / \mathrm{r}$ and Cdh5CreER::II1 $\mathrm{r} 1 \mathrm{r} / \mathrm{r}$ mice ( $\mathrm{n}=8$ mice per group). (G) Schematic diagram showing the genetic design of the Cdh5CreER::II1r1fl/fl mouse line. $(\mathrm{H})$ Quantification of II1r1 gene expression in primary endothelial cells isolated from the spinal cord of $I 11 \mathrm{r} 1 \mathrm{fl} / \mathrm{fl}$ mice, which normally express the $\| 1 \mathrm{r} 1$ gene (set to $100 \%$ ), and Cdh $5 \mathrm{CreER}: . \| 1 \mathrm{r} 1 \mathrm{fl} / \mathrm{fl}$ mice at 30 days post-tamoxifen treatment. (I) Quantification of the total number of Ly6G + neutrophils that infiltrated the spinal cord of WT, II1 r1 fl/fl, and Cdh5CreER::II1 r1fl/fl mice at 24 hours post-injection of either PBS or rmlL-1a ( $\mathrm{n}=8-12$ mice/group). (J) Quantification of the total number of Olig2+ CC1+ mature OLs in the spinal cord white matter of WT, $\| 1 \mathrm{r} 1 \mathrm{fl} / \mathrm{fl}$, and Cdh5CreER::.l1 $\mathrm{r} 1 \mathrm{fl} / \mathrm{fl}$ mice at 24 hours post-injection of either PBS or rmIL-1a ( $\mathrm{n}=6-11$ mice/group). (K-L) Locomotor function was assessed using the BMS score (K) and BMS subscore (L) over a 35-day period after $\mathrm{SCl}$ in WT, Il1 r1 fl/fl, and Cdh5CreER::.ll1 $1 \mathrm{fl} / \mathrm{fl}$ mice ( $\mathrm{n}=7-8$ mice per group). Statistical significance was determined by either a Student's t-test (B, H), two-way ANOVA (C-D, I-J), or two-way repeated measures ANOVA $(E-F, K-L)$ followed by a Bonferroni post-hoc test. ${ }^{\star \star \star \star} p<0.0001$, $* \star \star$ $p<0.001,{ }^{* *} p<0.01, * p<0.05, I 11 \mathrm{r} 1 \mathrm{r} / \mathrm{r}$ mice compared to WT mice $(E-F) . \& \& \& \& p<0.0001, \& \& \& p<$ $0.001, \& \& p<0.01, \& p<0.05$, Cdh5CreER::I11 r1 r/r mice compared to WT mice (E-F). Other pairwise comparisons and $\mathrm{p}$-values are indicated in the graphs. 
a

Restoration of $/ / 1 \mathrm{r}^{\mathrm{rr}}$ allele

LoxP LoxP TAG

with cre

Restored $\| 11 r 1$ allele
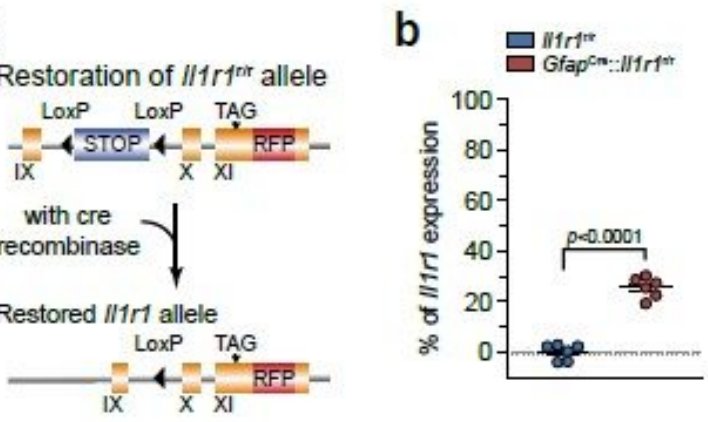

e

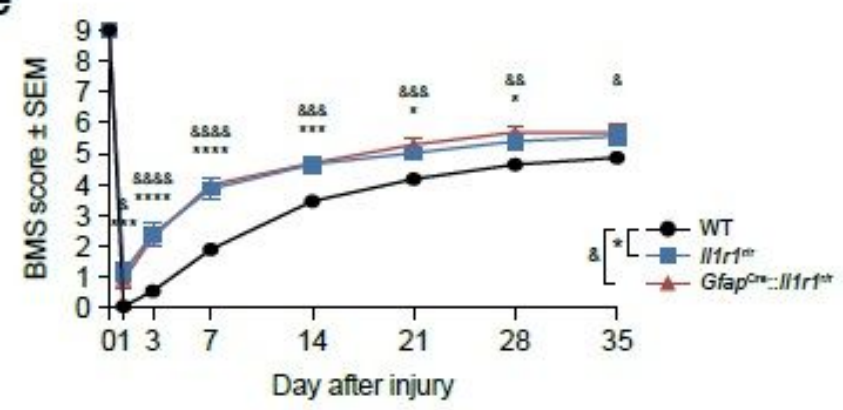

c

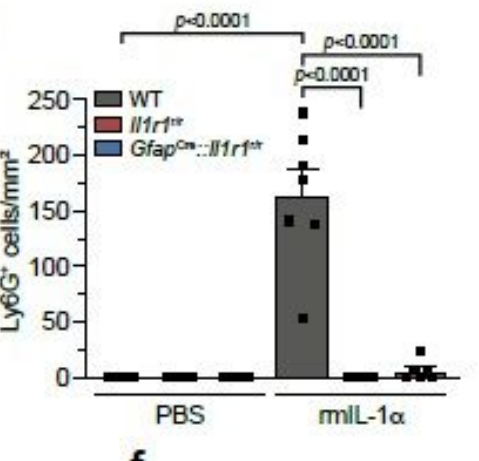

f

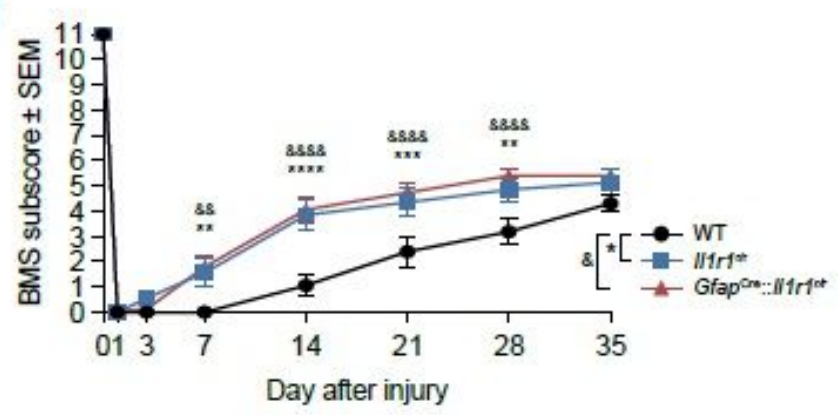

g

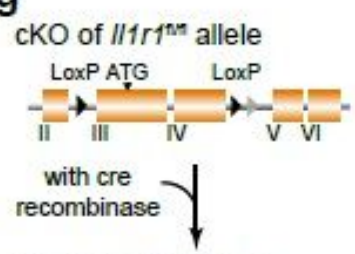

Knockout of $\| 11 r 1$ allele

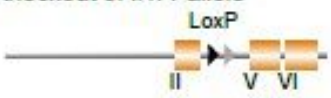

k

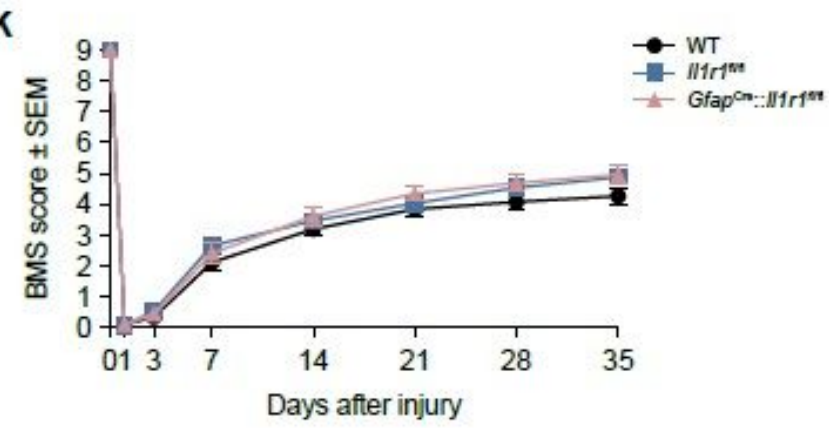

i
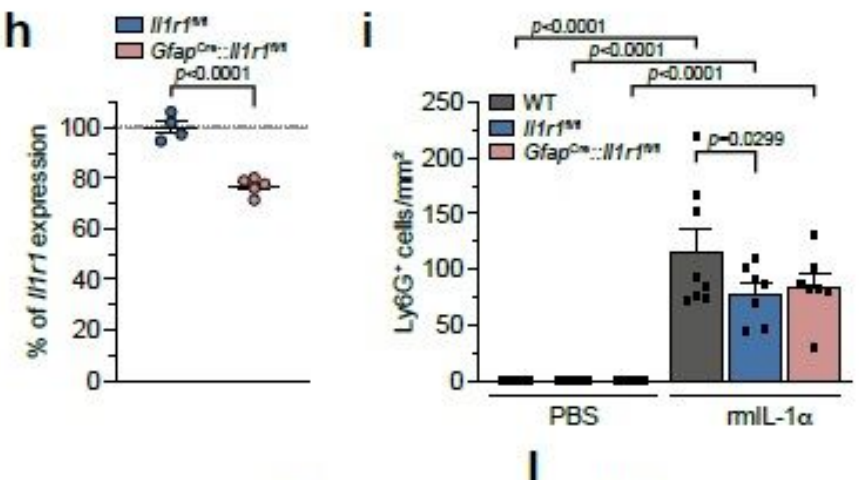

j

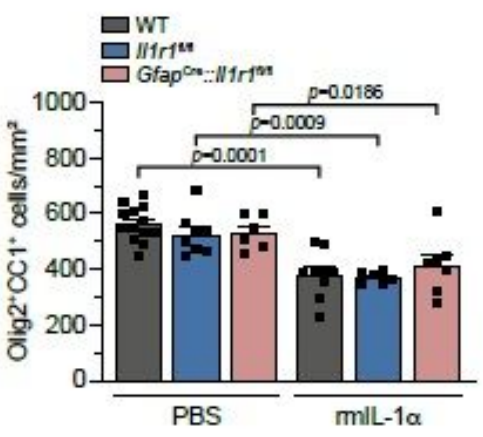

I

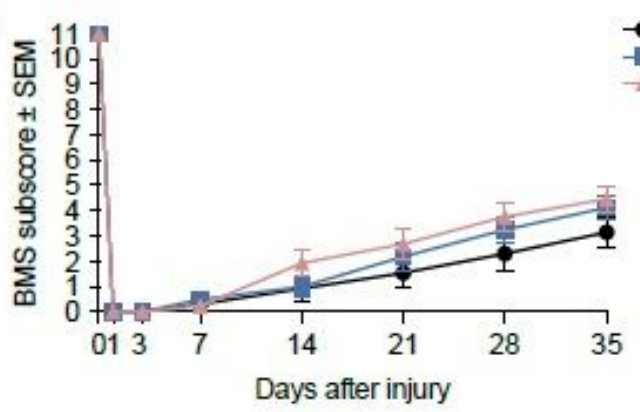

\section{Figure 9}

IL-1a-induced neuroinflammation and oligodendrocyte loss is partly mediated by astrocytic IL-1R1. (A) Schematic diagram showing the genetic design of the GfapCre::I11 $r 1 \mathrm{r} / \mathrm{r}$ mouse line. (B) Quantification of restoration of $\| 1 \mathrm{r} 1$ gene expression in primary astrocytes isolated from the brain of neonate $\| 1 \mathrm{r} 1 \mathrm{r} / \mathrm{r}$ mice, which express an IL-1R1-knockout phenotype (set to 0\%), and GfapCre::I11r1r/r mice. (C) Quantification of the total number of Ly6G+ neutrophils that infiltrated the spinal cord of WT, $I 11 \mathrm{r} 1 \mathrm{r} / \mathrm{r}$ and GfapCre::II $1 \mathrm{r} 1 \mathrm{r} / \mathrm{r}$ mice at 24 hours post-injection of either PBS or recombinant mouse (rm) IL-1a intra-cisterna magna ( $\mathrm{n}=5$ 8 mice/group). (D) Quantification of the total number of Olig2+ CC1+ mature OLs in the spinal cord white 
matter of WT, II1r1r/r and GfapCre::II $1 \mathrm{r} 1 \mathrm{r} / \mathrm{r}$ mice at 24 hours post-injection of either PBS or rmIL-1a ( $\mathrm{n}=6-8$ mice/group). (E-F) Locomotor function was assessed using the BMS score (E) and BMS subscore (F) over a 35-day period after SCI in WT, II1 $r 1 r / r$ and GfapCre:: $\| 1 \mathrm{r} 1 \mathrm{r} / \mathrm{r}$ mice ( $\mathrm{n}=15-16$ mice per group). (G) Schematic diagram showing the genetic design of the GfapCre::Il1 $1 \mathrm{fl} / \mathrm{fl}$ mouse line. $(\mathrm{H})$ Quantification of $\| 1 \mathrm{r} 1$ gene expression in primary astrocytes isolated from the brain of neonate $\| 1 \mathrm{r} 1 \mathrm{fl} / \mathrm{fl}$ mice, which normally express the $111 \mathrm{r} 1$ gene (set to $100 \%$ ), and GfapCre::II1 r1fl/fl mice. (I) Quantification of the total number of Ly6G+ neutrophils that infiltrated the spinal cord of WT, $\| 1 \mathrm{r} 1 \mathrm{fl} / \mathrm{fl}$ and GfapCre::II $1 \mathrm{r} 1 \mathrm{fl} / \mathrm{fl}$ mice at 24 hours post-injection of either PBS or rmIL-1a ( $n=7-13$ mice/group). (J) Quantification of the total number of Olig2 + CC1+ mature OLs in the spinal cord white matter of WT, II $1 \mathrm{r} 1 \mathrm{fl} / \mathrm{fl}$ and GfapCre::Il1 $1 \mathrm{r} f \mathrm{fl} f$ mice at 24 hours post-injection ( $\mathrm{n}=7-13$ mice/group). (K-L) Locomotor function was assessed using the BMS score (K) and BMS subscore (L) over a 35-day period after SCl in WT, II1 $\mathrm{r} 1 \mathrm{fl} / \mathrm{fl}$ and GfapCre::Il1 $1 \mathrm{r}$ fl/fl mice ( $n=13-16$ mice per group). Statistical significance was determined by either a Student's t-test $(B, H)$, two-way ANOVA (C-D, I-J), or two-way repeated measures ANOVA (E-F, K-L) followed by a Bonferroni posthoc test. $* \star \star \star ~ p<0.0001, * \star \star p<0.001, * \star p<0.01,{ }^{*} p<0.05, \| 1 \mathrm{r} 1 \mathrm{r} / \mathrm{r}$ mice compared to WT mice (E-F). $\& \& \& \& p<0.0001, \& \& \& p<0.001, \& \& p<0.01, \& p<0.05$, GfapCre::I11 $r 1 r / r$ mice compared to WT mice (E$F)$. Other pairwise comparisons and $p$-values are indicated in the graphs. 
PBS

a

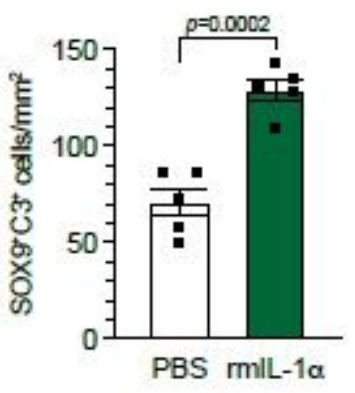

d

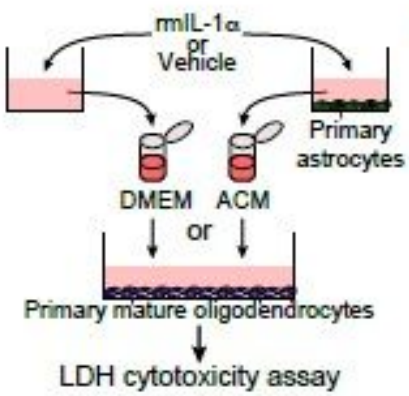

Saline $+r m I L-1 \alpha$
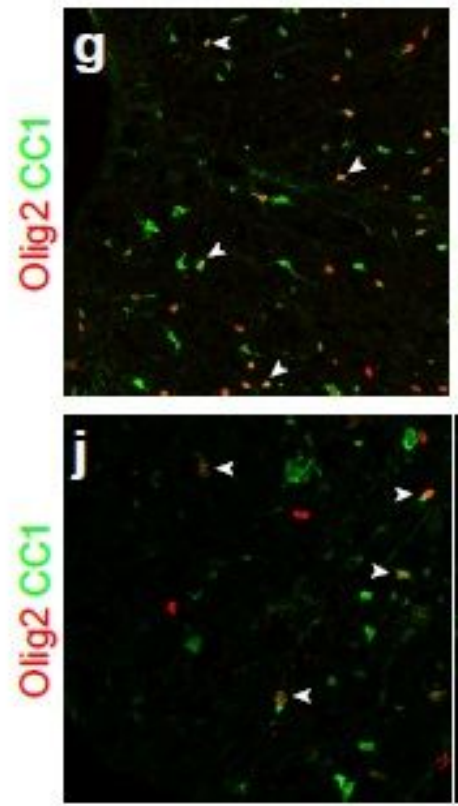
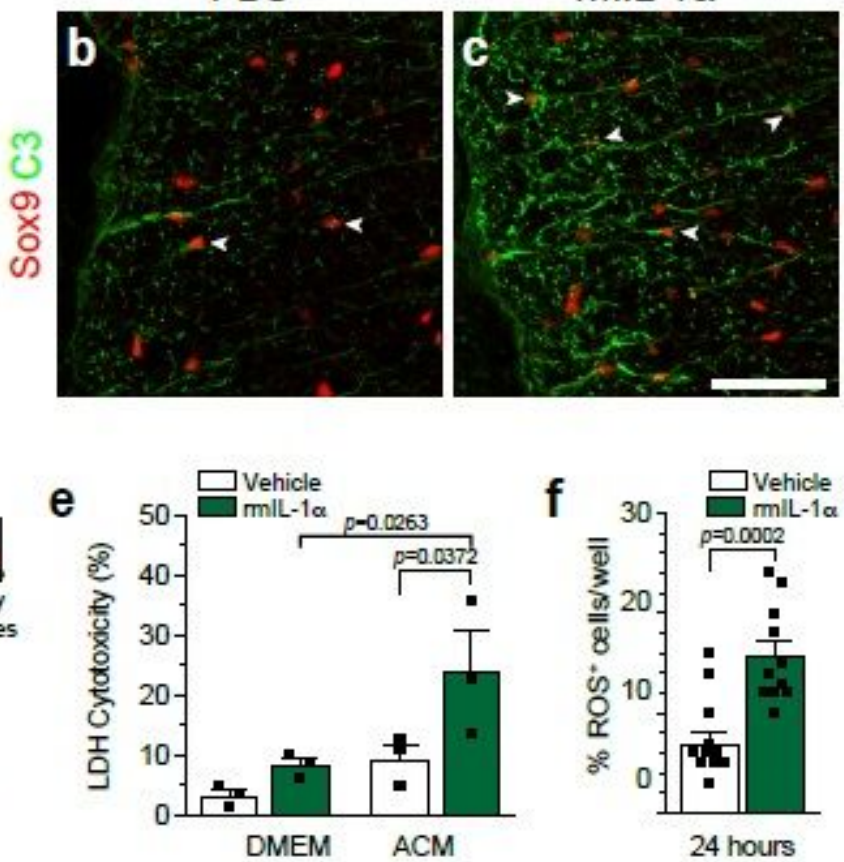

$\mathrm{NAC}+\mathrm{rmlL}-1 \alpha$
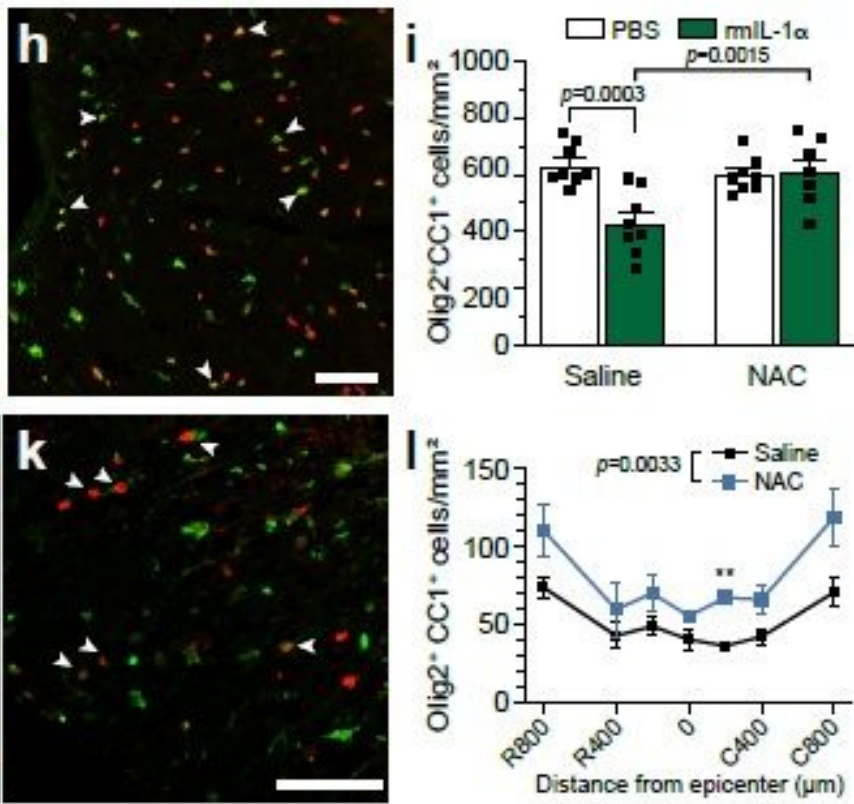

\section{Figure 10}

Reactive oxygen species released by astrocytes in response to IL-1a induce oligodendrocyte death. (A) Quantification of the total number of Sox9+C3+ astrocytes in the spinal cord white matter of C57BL/6 mice injected intra-cisterna magna (i.c.m.) with either PBS or recombinant mouse (rm) IL-1a and killed at day 1 post-injection ( $n=5$ mice/group). (B-C) Representative confocal images showing Sox 9 (a marker of astrocytes, red) and C3 (green) immunostainings in the spinal cord of mice injected i.c.m. with PBS (B) or rmIL-1a (C). White arrowheads point to some double-labeled cells. (D) Schematic diagram showing the 
experimental design for the lactate dehydrogenase (LDH) assay used to determine the cytotoxicity of primary oligodendrocytes (OLs) in vitro. Primary astrocytes were cultured in the presence of either PBS (vehicle) or rmIL-1a. Primary mature OLs were then incubated in control DMEM medium containing (or not) rmIL-1a, or in conditioned medium derived from astrocytes (ACM) stimulated with either PBS (vehicle) or IL-1a. (E) Quantification of OL loss using the LDH cytotoxicity assay. (F) Quantification of reactive oxygen species (ROS) production in primary astrocytes stimulated with either PBS (vehicle) or rmIL-1a (10 ng/mL). The detection of ROS was performed using the CellROX Green Reagent (green). (GH) Representative confocal images showing immunostaining for the Olig2 transcription factor (a marker of cells of the OL lineage, red cells) and CC1 (a marker of mature OLs, green) in the spinal cord of C57BL/6 mice injected i.c.m. with rmIL-1 $\mathrm{a}$ and treated i.p. with either N-acetyl-L-cysteine (NAC, an antagonist of ROS activity) or saline. Mice were killed at 24 hours post-i.c.m. injection. (I) Quantification of the total number of Olig2+ CC1+ mature OLs in the spinal cord white matter of PBS- and IL-1a-injected mice following treatment with either NAC or saline ( $n=8$ mice/group). (J-K) Representative confocal images taken at the lesion epicenter showing immunostaining for Olig2 (green) and CC1 (red) at day 1 post-SCI in C57BL/6 mice treated with either NAC or saline. (L) Quantification of the number of Olig2+ $\mathrm{CC} 1+$ oligodendrocytes in the injured spinal cord of mice treated with NAC or saline and killed at day 1 post-SCI ( $n=3-5 /$ group). Statistical significance was determined by either a Student's t-test (A, F) or twoway ANOVA followed by a Bonferroni post-hoc test $(E, I, L)$. ${ }^{*} p<0.01$, compared with the saline group $(L)$. Other pairwise comparisons and p-values are indicated in the graphs. Scale bars: (B-C, in C) $50 \mu \mathrm{m},(\mathrm{G}-\mathrm{H}$, in $\mathrm{H}) 50 \mu \mathrm{m},(\mathrm{J}-\mathrm{K}$, in $\mathrm{K}) 50 \mu \mathrm{m}$.

\section{Supplementary Files}

This is a list of supplementary files associated with this preprint. Click to download.

- SupplementaryFiguresBretheauetal.pdf

- ReportingSummaryNCOMMS2121054.pdf 